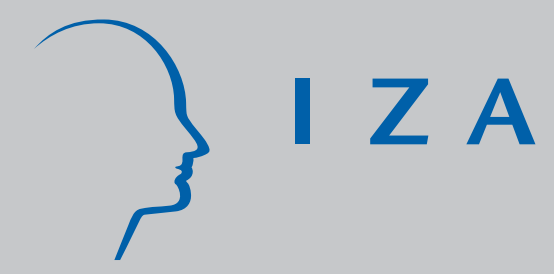

IZADP No. 2137

The Intrahousehold Allocation of Private and Public Consumption:

Theory and Evidence from U.S. Data

Olivier Donni

May 2006 


\title{
The Intrahousehold Allocation of Private and Public Consumption: Theory and Evidence from U.S. Data
}

\author{
Olivier Donni \\ THEMA, University of Cergy-Pontoise \\ and IZA Bonn
}

Discussion Paper No. 2137

May 2006

IZA

P.O. Box 7240

53072 Bonn

Germany

Phone: +49-228-3894-0

Fax: +49-228-3894-180

Email: iza@iza.org

Any opinions expressed here are those of the author(s) and not those of the institute. Research disseminated by IZA may include views on policy, but the institute itself takes no institutional policy positions.

The Institute for the Study of Labor (IZA) in Bonn is a local and virtual international research center and a place of communication between science, politics and business. IZA is an independent nonprofit company supported by Deutsche Post World Net. The center is associated with the University of Bonn and offers a stimulating research environment through its research networks, research support, and visitors and doctoral programs. IZA engages in (i) original and internationally competitive research in all fields of labor economics, (ii) development of policy concepts, and (iii) dissemination of research results and concepts to the interested public.

IZA Discussion Papers often represent preliminary work and are circulated to encourage discussion. Citation of such a paper should account for its provisional character. A revised version may be available directly from the author. 


\section{ABSTRACT \\ The Intrahousehold Allocation of Private and Public Consumption: Theory and Evidence from U.S. Data*}

We adopt the collective approach to consumer behavior with egoistic agents, and assume that the household consumption is either private or public. We then show that (i) household demands have to satisfy testable constraints and (ii) some elements of the decision process can be retrieved from observed behavior. These results are based on a conditional demand ('m-demand') framework in which household demands are directly derived from the marginal rates of substitution. Finally, we present an empirical application using the U.S. Consumer Expenditure Survey. Overall, the data turn out to be consistent with the theoretical model.

JEL Classification: D11, D12, H41

Keywords: collective decision, intra-household distribution, demand analysis, private good, public good, Lindahl price

Corresponding author:

Olivier Donni

University of Cergy-Pontoise

33, Boulevard du Port

95011 Cergy-Pontoise Cedex

France

Email: olivier.donni@eco.u-cergy.fr

\footnotetext{
Preliminary versions of this paper have been presented at the ESEM 2002 (Venise), the CEA Congress 2002 (Calgary) and several seminars and workshops in Paris, Rennes, Copenhagen, Quebec, Sherbrooke, Ottawa. I specially thank Bernard Lejeune for a GMM gauss package and valuable discussions. I am also grateful to François Bourguignon, Martin Browning, Pierre-André Chiappori, Anyck Dauphin, Bernard Fortin, Alain Guay, Guy Lacroix, Nicolas Marceau, André Masson, Philip Merrigan, Bernard Salanié for useful comments and suggestions. Of course, I bear the sole responsability for any remaining errors.
} 


\section{Introduction}

During the recent years the so-called 'collective' approach to household behavior, developed by Chiappori $(1988,1992)$, has attracted increasing attention from the profession. This approach basically relies on two assumptions: each person in the household is characterized by specific preferences, and the intra-household decision process results in Pareto efficient outcomes. ${ }^{1}$ This contrasts with the 'unitary' approach which postulates that the household can be represented by a single utility function.

There are two separate branches of literature that investigate household consumption within the collective framework. On the one hand, Bourguignon et alii (1993), Browning et alii (1994) and Bourguignon, Browning and Chiappori (1995) provide the theoretical background when prices are assumed constant. These authors show that, in general, collective household demands have to satisfy testable restrictions under the form of partial differential equations. Moreover, in the particular case of egoistic agents with purely private consumption, efficiency implies that the intra-household decision process can be decentralized by application of the Theorems of Welfare Economics. In a first step, members divide household income according to some predetermined rule which depends on the household environment. In a second step, they maximize their utility subject to their own budget constraint. One of the most important theoretical results is then that the sharing rule for household income can generally be retrieved, up to an additive constant, from the observation of household demands. This is essential to the study of welfare at the individual level. On the other hand, Browning and Chiappori (1998), Chiappori and Ekeland $(2003,2006)$ and Donni (2006) consider the case of variable prices. This generates further theoretical restrictions on household behavior. In particular, these authors show that, under Pareto efficiency, the substitution matrix of the household demand system has to be equal to the sum of a symmetric matrix and an outer product.

In the present paper, we follow the second line of research where prices vary. Our

\footnotetext{
${ }^{1}$ Recent surveys of this literature are given by Vermeulen (2002) and Donni (2006).
} 
model postulates that agents are egoistic ${ }^{2}$ and that consumption is either public or private. We then derive a set of very simple constraints that allows us to test efficiency (in the particular context of egoistic agents) and show that some elements of the household decision process can be recovered from observed behavior. More precisely, our identification results are twofold. Firstly, individual demands for private goods and individual prices for public goods are partially identifiable if there is no additional assumption on preferences. Secondly, individual demands and individual prices are completely identifiable if preferences are such that public goods are separable from other goods. These contributions contrast with the majority of identification results which - in spite of the fact that the existence of joint consumption is one of the main 'economic' justifications for the formation of a couple - crucially relies on the privateness of household consumption.

The proofs of all the results in this paper are based on a theoretical innovation, namely, a collective generalization of the 'marginal' demands that were previously studied by Browning (1999) for the unitary approach. In this generalization, the quantities of private goods and the prices of public goods are modeled as functions of the prices of private goods, the quantities of public goods, and the quantities of two reference goods (one reference good must be exclusively consumed by the husband and the other by the wife). The idea is that the levels of these goods, if they are normal, represent a convenient indicator of the distribution of resources within the household. ${ }^{3}$ The advantages of this specification are then twofold. First, it provides a particularly simple and intuitive way to describe the intra-household decision process. Second, as will become clearer below, the modeling of these within-period collective marginal demands is compatible with a life-cycle allocation rule and robust to some controversial assumptions often made for

\footnotetext{
${ }^{2}$ Indeed, the assumption of egoism, or 'caring' in a sense that will be explained below, is essential to obtain interesting identification results, as previously made clear by Chiappori and Ekeland (2003).

${ }^{3}$ The concept of conditional demands used in the present paper differs from the conditional demands exploited by Bourguignon, Browning and Chiappori (1995), Dauphin and Fortin (2001), Donni (2006) and Donni and Moreau (2005) .
} 
intertemporal allocations. ${ }^{4}$

The theoretical considerations are followed by empirical evidence using the U.S. Consumer Expenditure Survey. We show that the constraints of the collective model are globally satisfied but the separability of private and public goods is definitively rejected. This implies that the model cannot be completely identified. Even in that case, however, useful structural components of the model can be recovered.

The role of public consumption is, undoubtedly, one of the main topical issues in the research agenda on collective models, as shown by several recent studies. Three contributions are related to ours. Chiappori, Blundell and Meghir (2006) investigate the identification issue in a collective model of labor supply with one private good and one public good. However, our results are in some respects more general, since we consider an arbitrary number of goods and assume that all prices may vary. ${ }^{5}$ Chiappori and Ekeland $(2003,2006)$ consider identification and testability in general collective models of consumption. These authors study the abstract characterization of household demands for groups of persons, but do not consider the question of identification in a model with both public and private goods. Finally, our work differs from these contributions on two additional points. First, we exploit the concept of marginal demands in the derivation of the main theoretical results; the latter turn out to be simple and intuitive. Second, we implement these theoretical results with consumption data.

This paper is structured as follows. In Section 2, we present the main theoretical results. We specify the assumptions, define the collective marginal demands, and derive the main theoretical results. In Section 3, the statistical model is specified. In Section 4,

\footnotetext{
${ }^{4}$ Mazzocco (2005) exploits the advantages of marginal demands to study the intertemporal allocation of consumption in a collective context. He also presents empirical evidence from the U.S. Consumer Expenditure Survey.

${ }^{5}$ Fong and Zhang (2001) consider a collective model of labor supply where, for each partner in a marriage, there are two distinct types of leisure: one type is each person's private (or independent) leisure and the other type is public (or spousal) leisure. This framework is very similar to that in Chiappori, Blundell and Meghir (2006).
} 
the data are described and the estimates are reported. In Section 5, concluding comments are given. All the proofs are collected in the appendix.

\section{Theory}

\subsection{Preferences, Goods and the Decision Process}

To begin, there are some goods in households that can reasonably be treated as private (e.g., food) and other goods that clearly have a strong public element (e.g., heating). This distinction is a familiar one and does not require a detailed discussion. However, if there is a good that only one person in the household cares about, we prefer to categorize such a good separately as exclusive rather than public or private. It will become clear below that the concept of exclusivity is essential in the theory which follows. An example of an exclusive good is 'clothing'. If there are no externalities and if the husband consumes only men's clothing and the wife consumes only women's clothing, then we can think of men's and women's clothing as two exclusive goods. ${ }^{6}$ This example will be exploited in the empirical part of this paper.

The main objective of this paper is to analyze consumption of private and public goods in a unified framework. To do so, we consider a two-member household. There are two exclusive goods, one for each person in the household. We suppose that life-cycle utility is strongly intertemporally separable and that the within-period preferences of member $i$ $(i=A, B)$ can be represented by a well-behaved utility function:

$$
u_{i}\left(x_{i}, \boldsymbol{q}_{i}, \boldsymbol{q}\right)
$$

where $x_{i}, \boldsymbol{q}_{i}$ and $\boldsymbol{q}$ respectively denote an exclusive good, a $N_{1}$-vector of private goods consumed by member $i$, and a $N_{2}$-vector of public goods consumed by the household.

\footnotetext{
${ }^{6} \mathrm{~A}$ pair of exclusive goods and one assignable good, i.e., a private good for which individual consumption can be observed, can be distinguished by the fact that the prices of two exclusive goods may independently vary.
} 
Several points must be stressed at this stage.

1. The agents are 'egoistic', in the sense that their utility only depends on their own consumption, but all the results of this paper can be extended to the case of 'caring' agents in a Beckerian sense, where agents actually maximize some 'altruistic' index:

$$
U_{i}\left[u_{A}\left(x_{A}, \boldsymbol{q}_{A}, \boldsymbol{q}\right), u_{B}\left(x_{B}, \boldsymbol{q}_{B}, \boldsymbol{q}\right)\right],
$$

where $U_{i}(\cdot)$ is a well-behaved utility function in $u_{A}$ and $u_{B}$.

2. All goods, whether public or private, are non-durable. One interpretation is that durable goods are separable from non-durable ones.

3. The individual demands for private goods $\boldsymbol{q}_{i}$ are treated as unobservable for the econometrician. The demand for these goods is only observed at the household level: $\boldsymbol{Q}=\boldsymbol{q}_{A}+\boldsymbol{q}_{B}$. On the contrary, the individual demands for exclusive goods $x_{i}$ are observable.

4. Each good can be unambiguously designated as purely public or purely private. This excludes the possibility of 'impure' goods, like leisure in Fong and Zhang's (2001) view. ${ }^{7}$

We assume that there is no domestic production. The household faces a linear budget constraint and non-negativity restrictions. Thus, the within-period budget set is given by

$$
\begin{gathered}
y \geqslant \sum_{i} x_{i} r_{i}+\sum_{i} \boldsymbol{q}_{i}^{\prime} \boldsymbol{p}+\boldsymbol{q}^{\prime} \boldsymbol{P}, \\
\boldsymbol{q} \geqslant 0, \quad \boldsymbol{q}_{i} \geqslant 0 \quad \text { and } \quad x_{i} \geqslant 0,
\end{gathered}
$$

where $r_{i}, \boldsymbol{p}$, and $\boldsymbol{P}$ respectively denote the price for the exclusive good, the $N_{1}$-vector of prices for private goods, and the $N_{2}$-vector of prices for public goods, $y$ denotes total expenditure (i.e., total income net of savings and expenditure on durable goods). The notation $\boldsymbol{P}$ (capitalized) for the price of public goods will become clearer in what follows.

\footnotetext{
${ }^{7}$ Some public goods in the model may, however, cover externalities in consumption.
} 
The originality of the collective approach lies in the fact that household decisions are assumed to result in Pareto-efficient outcomes and that no additional assumption is made about the decision process. ${ }^{8}$ That means that there exists a scalar $\phi$ such that household behavior can be described as the solution to the following program:

$$
\max _{\left\{x_{A}, x_{B}, \boldsymbol{q}_{A}, \boldsymbol{q}_{B}, \boldsymbol{q}\right\}} \phi \cdot u_{A}\left(x_{A}, \boldsymbol{q}_{A}, \boldsymbol{q}\right)+(1-\phi) \cdot u_{B}\left(x_{B}, \boldsymbol{q}_{B}, \boldsymbol{q}\right),
$$

subject to constraints (3). The scalar $\phi$ can be interpreted as a 'distribution of power' index. It generally depends on all the exogenous variables that may affect the intrahousehold distribution of power:

$$
\phi=\phi\left(r_{A}, r_{B}, y, \boldsymbol{p}, \boldsymbol{P}, \boldsymbol{s}\right),
$$

where $s$ is a vector of distribution factors. These factors are variables which, by definition, influence the decision process but do not affect the budget constraint (3) or preferences (1). Thus, the various household incomes can enter the vector of distribution factors (since the budget constraint of the household is determined by the level of total expenditure). There are other examples that can be found in the literature, though. Becker (1991) and Chiappori, Fortin and Lacroix (2002) underline the role of the state of the market for marriage and the specific features of divorce legislation. Thomas, Contreras and Frankenberg (1997) show that the distribution of wealth by gender at the time of the marriage may also be important.

\subsection{Collective Marginal Demands}

In the unitary approach, the marginal demand ('m-demand') for a good is defined as a function of the quantity of another reference good rather than total expenditure or the marginal utility of money. These demands, which have often been exploited (either explicitly or implicitly) in life-cycle analysis of household behavior (Altonji, 1986, and Meghir and Weber, 1996), are studied by Browning (1999).

\footnotetext{
${ }^{8}$ The justification of the efficiency hypothesis is discussed, among others, by Chiappori (1988, 1992).
} 
In what follows, we show that the study of household behavior from a collective viewpoint is especially simple when a generalization of m-demands is used. Let us denote by $\lambda$ the Lagrangian multiplier of the program $(\overline{\mathrm{P}})$ corresponding to the budget constraint, and we define $\phi_{A}=\phi$ and $\phi_{B}=1-\phi$. For an internal solution, the first-order conditions of the program $(\overline{\mathrm{P}})$ are then given by

$$
\frac{\phi_{i}}{\lambda} \frac{\partial u_{i}}{\partial x_{i}}=r_{i} \quad \text { and } \quad \frac{\phi_{i}}{\lambda} \frac{\partial u_{i}}{\partial \boldsymbol{q}_{i}}=\boldsymbol{p}
$$

for the allocation of exclusive and private goods, and

$$
\sum_{i} \frac{\phi_{i}}{\lambda} \frac{\partial u_{i}}{\partial \boldsymbol{q}}=\boldsymbol{P}
$$

for the allocation of public goods.

The cm-demands for private goods. We can now define the system of collective marginal demands, in terms of quantity, that are used to analyze private consumption (for the sake of conciseness, these are referred to as 'cm-demands for private goods' in the remainder of this text). To do that, we eliminate $\lambda$ and $\phi_{i}$ in the first-order conditions (5) and obtain:

$$
\frac{\partial u_{i} / \partial \boldsymbol{q}_{i}}{\partial u_{i} / \partial x_{i}}=\frac{\boldsymbol{p}}{r_{i}} .
$$

We suppose that this system of $N_{1}$ equations can be uniquely solved for $\boldsymbol{q}_{i}$ as a function of $r_{i}, x_{i}, \boldsymbol{p}$ and $\boldsymbol{q}$. We obtain the (individual) cm-demands for private goods:

$$
\boldsymbol{q}_{i}=\boldsymbol{q}_{i}\left(r_{i}, x_{i}, \boldsymbol{p}, \boldsymbol{q}\right) .
$$

Since we generally do not observe individual consumption in surveys, we shall study the (aggregate) cm-demands for private goods:

$$
\boldsymbol{Q}=\sum_{i} \boldsymbol{q}_{i}\left(r_{i}, x_{i}, \boldsymbol{p}, \boldsymbol{q}\right) .
$$

The cm-demands for public goods. We can also define the system of collective marginal demands, in terms of prices, that are used to analyze public consumption (' $\mathrm{cm}-$ demands for public goods'). We eliminate $\lambda$ and $\phi_{i}$ in the first-order condition (6) and 
obtain Samuelson's allocation rule for public consumption:

$$
\boldsymbol{P}=\sum_{i} r_{i} \frac{\partial u_{i} / \partial \boldsymbol{q}}{\partial u_{i} / \partial x_{i}}
$$

If we eliminate $\boldsymbol{q}_{i}$ in this expression, using equation (8), we obtain the (aggregate) cmdemands for public goods:

$$
\boldsymbol{P}=\sum_{i} \boldsymbol{p}_{i}\left(r_{i}, x_{i}, \boldsymbol{p}, \boldsymbol{q}\right)
$$

where $\boldsymbol{p}_{i}$ corresponds to the (individual) cm-demands for public goods, or the Lindahl prices, i.e., the price at which each member values her or his public consumption. ${ }^{9}$

The cm-demands, defined by equations (9) and (11), can be directly estimated with usual techniques since the variables on the left-hand side and the right-hand side are observable. Of course, in empirical work, we shall have to account for the probable endogeneity of the quantity of the exclusive and public goods.

Before continuing, we have to derive a sufficient condition for the existence of the cmdemands for private goods, and consequently of the cm-demands for public goods. This is made with the following assumption.

Assumption A1 The exclusive goods are conditionally normal, i.e., $\partial \chi_{i} / \partial \rho_{i}>0$, where $x_{i}=\chi_{i}\left(r_{i}, \boldsymbol{p}, \boldsymbol{q}, \rho_{i}\right)$ is the Marshallian demand for $x_{i}$ (conditional on $\boldsymbol{q}$ ) and $\rho_{i}=r_{i} x_{i}+$ $\boldsymbol{p}^{\prime} \boldsymbol{q}_{i}$ is the level of expenditure on private and exclusive goods by member $i$.

The role of this assumption is explained by Browning (1999). The intuition is that the first order conditions (7), with the corresponding budget constraint, $\rho_{i}=r_{i} x_{i}+\boldsymbol{p}^{\prime} \boldsymbol{q}_{i}$, define a system of Marshallian demands (conditional on the quantity of public goods $\boldsymbol{q}$ ). Now, if (conditional) normality is assured, the quantity of the exclusive good $x_{i}$ can be seen as a satisfactory indicator of the level of total expenditure $\rho_{i}$ and can be substituted for it in the Marshallian demands. This defines the individual cm-demands for private goods. In a certain sense, the pair of exclusive goods can be seen as 'sufficient statistics'

\footnotetext{
${ }^{9}$ Some Lindahl prices are possibly negative since public goods can be seen as an externality in consumption; see Myles (1995) for a discussion of Lindahl prices.
} 
for the level of household private consumption and the distribution of this consumption within the household. For example, if a person in the household consumes a lot of her or his personal exclusive good, and if this good is normal, then we can expect that this person will consume a lot of private goods in general. Incidentally, the cm-approach is in line with the recent recognition that consumption may better reflect expected lifetime resources than current income. In addition, income reported in surveys may also be an insufficient indicator of material well-being because of misreporting, mismeasurement or (in-kind) transfers among extended families or friends; see Cutler and Katz (1992) and Slesnick (1993) for this argument.

\subsection{Characterization}

In what follows, we assume that A1 is globally satisfied. Any cm-demand has, naturally, specific properties that can be used to check ex post the adequacy of the theory to observed behavior.

First of all, cm-demands have to be homogeneous. This is formally stated in the next proposition.

Proposition 1 Under collective rationality with egoistic agents and A1,

1. The cm-demands for private goods $\boldsymbol{Q}\left(r_{A}, r_{B}, x_{A}, x_{B}, \boldsymbol{p}, \boldsymbol{q}\right)$ are homogeneous of degree 0 in $r_{A}, r_{B}$ and $\boldsymbol{p}$;

2. The cm-demands for public goods $\mathbf{P}\left(r_{A}, r_{B}, x_{A}, x_{B}, \boldsymbol{p}, \boldsymbol{q}\right)$ are homogeneous of degree 1 in $r_{A}, r_{B}$ and $\boldsymbol{p}$.

One remarkable point here is that the homogeneity of cm-demands does not follow from the homogeneity of the distribution function $\phi$. In other words, cm-demands will be homogeneous even if the bargaining power of household members is affected by money illusion. 
The remaining restrictions are twofold. First, the additive structure of cm-demands can be translated into testable restrictions in the form of partial differential equations. This is what we call 'c-separability', where 'c' stands for 'consumption'. Second, household behavior is characterized by a symmetry property, as in Browning and Chiappori (1998), which results from the optimization problem. To exhibit these properties, we use the following conventions:

$$
\boldsymbol{d}_{i}^{\prime}=\left(\boldsymbol{q}_{i}^{\prime},-\boldsymbol{p}_{i}^{\prime}\right), \quad \boldsymbol{m}^{\prime}=\left(\boldsymbol{p}^{\prime}, \boldsymbol{q}^{\prime}\right)
$$

and

$$
\boldsymbol{D}=\sum_{i} \boldsymbol{d}_{i}\left(r_{i}, x_{i}, \boldsymbol{m}\right)
$$

where $\boldsymbol{D}^{\prime}=\left(\boldsymbol{Q}^{\prime},-\boldsymbol{P}^{\prime}\right)$. This notation turns out to be very convenient and is used throughout the remainder of the paper. Now, we formally introduce the following proposition.

Proposition 2 Under collective rationality with egoistic agents and A1,

1. $\frac{\partial^{2} \boldsymbol{D}}{\partial x_{A} \partial x_{B}}=\frac{\partial^{2} \boldsymbol{D}}{\partial r_{A} \partial x_{B}}=\frac{\partial^{2} \boldsymbol{D}}{\partial x_{A} \partial r_{B}}=\frac{\partial^{2} \boldsymbol{D}}{\partial x_{A} \partial x_{B}}=\mathbf{0}$;

2. $\left(\frac{\partial \boldsymbol{D}}{\partial \boldsymbol{m}^{\prime}}+\sum_{i} \frac{\partial \boldsymbol{D}}{\partial x_{i}} \frac{\partial \boldsymbol{D}^{\prime}}{\partial r_{i}}\right)$ is a symmetric matrix.

The first statement in this proposition (c-separability) yields a particularly simple test of collective rationality. ${ }^{10}$ Specifically, it necessitates the verification that four crossterms in a second-order approximation of the cm-demands are equal to zero. This may be realized with single equation methods. The second statement is a translation of Slutsky symmetry into the cm-context. This condition generalizes in two directions a symmetry property previously derived by Browning (1999, Proposition 1) in the unitary framework: first, the household is characterized by two decision makers and, second, some demands are implicitly represented with their prices as dependent variables. Note that these two sets of restrictions are not sufficient. In particular, the cm-demands also have to satisfy a property of negativity, which is more complicated to derive, though.

\footnotetext{
${ }^{10}$ To be precise, this is a joint test of various auxiliary assumptions: egoistic agents, absence of domestic production and absence of impure goods.
} 


\subsection{Identification: The General Case}

The next important result of this section concerns the identification of structural elements of the decision process from the estimation of cm-demands. We can put forward the following proposition.

Proposition 3 Under collective rationality with egoistic agents and A1,

1. The individual cm-demands for private goods $\boldsymbol{q}_{i}\left(r_{i}, x_{i}, \boldsymbol{m}\right)$ can be retrieved up to an additive function $\boldsymbol{g}_{i}(\boldsymbol{m})$;

2. The individual cm-demands for public goods $\boldsymbol{p}_{i}\left(r_{i}, x_{i}, \boldsymbol{m}\right)$ can be retrieved up to an additive function $\boldsymbol{h}_{i}(\boldsymbol{m})$;

3. The functions $\boldsymbol{g}_{i}(\boldsymbol{m}), \boldsymbol{h}_{i}(\boldsymbol{m})$ and $\boldsymbol{f}_{i}^{\prime}(\boldsymbol{m})=\left[\boldsymbol{g}_{i}^{\prime}(\boldsymbol{m}), \boldsymbol{h}_{i}^{\prime}(\boldsymbol{m})\right]$ have to satisfy the following properties:

$$
\sum_{i} \boldsymbol{f}_{i}=\mathbf{0}, \quad \frac{\partial \boldsymbol{g}_{i}}{\partial \boldsymbol{p}^{\prime}} \boldsymbol{p}=\mathbf{0}, \quad \frac{\partial \boldsymbol{h}_{i}}{\partial \boldsymbol{p}^{\prime}} \boldsymbol{p}=\boldsymbol{h}_{i}, \quad \frac{\partial \boldsymbol{f}_{i}}{\partial \boldsymbol{m}^{\prime}}=\frac{\partial \boldsymbol{f}_{i}^{\prime}}{\partial \boldsymbol{m}}
$$

The first two statements of this proposition straightforwardly result from the fact that the derivatives of the individual cm-demands with respect to $r_{i}$ and $x_{i}$ coincide with that of the aggregate $\mathrm{cm}$-demands. The third statement translates the fact that individual cm-demands must satisfy restrictions of homogeneity and symmetry as well. This reduces the indeterminacy on the functions $\boldsymbol{g}_{i}(\boldsymbol{m})$ and $\boldsymbol{h}_{i}(\boldsymbol{m})$. Now, note that, even if the identification of the basic components of the model is not complete - the functions $\boldsymbol{g}_{i}(\boldsymbol{m})$ and $\boldsymbol{h}_{i}(\boldsymbol{m})$ remain undefined - this result proves attractive. At this stage, it indicates that differences in tastes between the husband and the wife can be revealed by the estimation of cm-demands.

The existence of a sharing rule is not explicitly postulated in the cm-demand context, unlike in the large majority of papers on collective models. However, it is possible to define the expenditure on private and exclusive goods of each household member as a 
function of $r_{i}, x_{i} \boldsymbol{p}$ and $\boldsymbol{q}$ as follows:

$$
\rho_{i}\left(r_{i}, x_{i}, \boldsymbol{m}\right)=x_{i} r_{i}+\boldsymbol{p}^{\prime} \boldsymbol{q}_{i}\left(r_{i}, x_{i}, \boldsymbol{m}\right) .
$$

This is a generalization of the sharing rule to public goods. Its derivatives with respect to $r_{i}$ and $x_{i}$ can obviously be identified. In particular, we have:

$$
\frac{\partial \rho_{i}}{\partial x_{i}}=r_{i}+\boldsymbol{p}^{\prime} \frac{\partial \boldsymbol{Q}}{\partial x_{i}} \quad \text { and } \quad \frac{\partial \rho_{i}}{\partial r_{i}}=x_{i}+\boldsymbol{p}^{\prime} \frac{\partial \boldsymbol{Q}}{\partial r_{i}}
$$

This result is reminiscent of previous results on the identification of the sharing rule with exclusive goods; see Browning et alii (1994) or Donni (2006), for instance. Moreover, from equations (13) and the following identity:

$$
x_{i} \equiv \chi_{i}\left[r_{i}, \boldsymbol{m}, \rho_{i}\left(r_{i}, x_{i}, \boldsymbol{m}\right)\right],
$$

the slope of the conditional Marshallian demand for exclusive goods can be readily obtained:

$$
\begin{aligned}
\frac{\partial \chi_{i}}{\partial \rho_{i}} & =\left(r_{i}+\boldsymbol{p}^{\prime} \frac{\partial \boldsymbol{Q}}{\partial x_{i}}\right)^{-1}, \\
\frac{\partial \chi_{i}}{\partial r_{i}} & =-\left(x_{i}+\boldsymbol{p}^{\prime} \frac{\partial \boldsymbol{Q}}{\partial r_{i}}\right)\left(r_{i}+\boldsymbol{p}^{\prime} \frac{\partial \boldsymbol{Q}}{\partial x_{i}}\right)^{-1}
\end{aligned}
$$

The idea that exclusive goods are normal, as demanded by A1, can thus be assessed with data. In addition, more powerful conclusions can be obtained with mild additional assumptions. For example, let us consider the following statement.

Assumption A2 The quantity of exclusive goods of each member is an appropriate indicator of bargaining power, i.e., if $\phi_{i}$ increases, leaving $y$ unaffected, then $x_{i}$ increases and $x_{j}$ decreases for $j \neq i$.

This assumption says that member $A$ (say) will consume a greater quantity of exclusive goods when her or his bargaining power increases (assuming that the level of total expenditure remains constant). This seems quite natural and does not merit discussion. 
This is implied by A1 when there are no public goods. Now, let us define a 'pure' variation in bargaining power as a variation in $\phi_{i}$ such that $y$ is kept constant. We have the following result.

Corollary 4 Let us assume that $\partial \boldsymbol{P} / \partial \boldsymbol{q}^{\prime}$ is invertible. Then, under collective rationality with egoistic agents, A1 and A2, the sign of the effect of a pure variation in bargaining power on the quantity of private and public goods demanded by the household is identified.

This corollary indicates, in particular, that the sign (negative or positive) of the effect on the demand for a public good (such as heating) of a shift in bargaining power can be predicted. ${ }^{11}$

\subsection{Identification: The Separable Case}

Thus, the identification of the individual cm-demands is incomplete: The function $\boldsymbol{f}_{i}(\boldsymbol{m})$ remains undetermined. A solution to this problem necessitates the addition of a structure on preferences. Fong and Zhang (2001) and Chiappori, Blundell and Meghir (2006) deal with this issue in a labor supply context. Basically, they assume that preferences are such that public goods are separable from other goods. Similarly, we assume the following:

Assumption A3 The individual utility functions are of the form: $u_{i}\left[\mu_{i}\left(x_{i}, \boldsymbol{q}_{i}\right), \boldsymbol{q}\right]$, where $\mu_{i}$ is a sub-utility function with the usual regularity conditions.

This assumption is certainly restrictive. Nevertheless, it should be emphasized that, to the best of our knowledge, such separability has never been tested in the literature until now. Now, if A3 is satisfied, the first-order conditions for the allocation of private goods become:

$$
\frac{\partial \mu_{i} / \partial \boldsymbol{q}_{i}}{\partial \mu_{i} / \partial x_{i}}=\frac{\boldsymbol{p}}{r_{i}}
$$

\footnotetext{
${ }^{11}$ The theory here does not say how a shift in bargaining power can be achieved, though, this point is now well documented in the literature. For example, it is clear that a public transfer to one person in the household should improve the situation of this person.
} 
If these equations are solved as previously, we obtain the cm-demands for private goods:

$$
\boldsymbol{Q}=\sum_{i} \boldsymbol{q}_{i}\left(r_{i}, x_{i}, \boldsymbol{p}\right)
$$

The remarkable point is that, under the assumption of separability, these equations do not depend on the level of public consumption. This is sufficient to identify some important elements of the decision process. We formally have the following proposition.

Proposition 5 Under collective rationality with egoistic agents, A1 and A3,

1. The individual cm-demands for private goods $\mathbf{q}_{i}\left(r_{i}, x_{i}, \boldsymbol{p}, \boldsymbol{q}\right)$ can be retrieved up to an additive function $\boldsymbol{g}_{i}(\boldsymbol{p})$;

2. The individual cm-demands for public goods $\boldsymbol{p}_{i}\left(r_{i}, x_{i}, \boldsymbol{p}, \boldsymbol{q}\right)$ can be exactly retrieved; in particular,

$$
\mathbf{p}_{i}=\left(\frac{\partial \boldsymbol{P}}{\partial r_{i}} \frac{\partial \boldsymbol{Q}^{\prime}}{\partial x_{i}}-\frac{\partial \boldsymbol{P}}{\partial x_{i}} \frac{\partial \boldsymbol{Q}^{\prime}}{\partial r_{i}}\right) \boldsymbol{p}+\frac{\partial \boldsymbol{P}}{\partial r_{i}} r_{i} ;
$$

3. Further testable restrictions on $\mathrm{cm}$-demands are generated.

The first statement of this proposition is a direct consequence of the fact that the cm-demands for private goods are independent of the quantity of public goods. That the function $\boldsymbol{g}_{i}(\boldsymbol{p})$ remains undetermined is not of great concern here. The important point for our purpose is that the individual demands for private goods can be derived when prices are constant (e.g., over a short period of time). The intuition behind the second statement is more complicated, but it can be grasped in the particular case of purely public consumption $\left(N_{1}=0\right)$. To do that, let us recall that individual prices are linearly homogeneous. Thus, if $N_{1}=0$, we have:

$$
\boldsymbol{p}_{i}=\frac{\partial \boldsymbol{P}}{\partial r_{i}} r_{i}
$$

from Euler's theorem. This relation identifies exactly the individual cm-demands for public goods $\boldsymbol{p}_{i}\left(r_{i}, x_{i}, \boldsymbol{q}\right) .{ }^{12}$ Now, the identification of the Lindhal prices given by equation

\footnotetext{
${ }^{12}$ Chiappori and Ekeland (2003) demonstrate a similar result in a slightly different context. However, the intuition of the identification in the cm-context is much simpler.
} 
(17) is simply a consequence of Euler's theorem in the general case of private and public goods. The term in parentheses this equation corresponds to the derivative of the Lindahl prices with respect to the prices of private goods.

\subsection{Preference Factors}

The present model can be generalized by the introduction of preference factors. Indeed, the preferences of each agent generally depend on a set of socio-demographic characteristics. Therefore, we may assume:

$$
u_{i}\left(x_{i}, \boldsymbol{q}_{i}, \boldsymbol{q} ; \boldsymbol{z}_{i}, \boldsymbol{z}\right)
$$

where $\boldsymbol{z}_{i}$ and $\boldsymbol{z}$ are called 'preference factors'. We must make an important, if a little artificial, distinction between factors such as $\boldsymbol{z}_{i}$ which seem to be related to a specific individual in the household (such as age, race, or level of education) and factors such as $\boldsymbol{z}$ which are common to both agents (such as the number and age of the children, the state or country of residence).

The next step is to define, as previously, the cm-demands 'extended' to preference factors. We follow the same approach as in the preceding section and readily obtain:

$$
\boldsymbol{D}=\sum_{i} \boldsymbol{d}_{i}\left(r_{i}, x_{i}, \boldsymbol{p}, \boldsymbol{q} ; \boldsymbol{z}_{i}, \boldsymbol{z}\right)
$$

The distinction between common and specific preference factors naturally generates further testable restrictions. This is what we call 'p-separability', where 'p' stands for 'preference'. This is formally expressed in the following proposition. Let $\boldsymbol{z}_{i}=\left(z_{i 1}, \ldots, z_{i k_{i}}, \ldots\right.$, $\left.z_{i K_{i}}\right)^{\prime}$ be a $K_{i}$-vector.

Proposition 6 Under collective rationality with egoistic agents and A1,

$$
\frac{\partial^{2} \boldsymbol{D}}{\partial z_{A k_{A}} \partial r_{B}}=\frac{\partial^{2} \boldsymbol{D}}{\partial z_{A k_{A}} \partial x_{B}}=\frac{\partial^{2} \boldsymbol{D}}{\partial z_{A k_{A}} \partial z_{B k_{B}}}=\frac{\partial^{2} \boldsymbol{D}}{\partial r_{A} \partial z_{B k_{B}}}=\frac{\partial^{2} \boldsymbol{D}}{\partial x_{A} \partial z_{B k_{B}}}=\mathbf{0},
$$

for any $k_{A}$ and $k_{B}$. 
This proposition provides a very simple test of the collective approach with egoistic agents, provided that a clear distinction between specific and common preference factors exists. This result is very useful in empirical applications because it is one of the very few results in the literature that restricts the influence of preference factors on household behavior. As such, it provides a simple way of limiting the number of parameters in the functional form. In addition, it is easy to show that the effect of the specific preference factors on the individual cm-demands can be identified as well.

\section{Statistical Specification}

In this section, we use a parametrization of the cm-demand system to derive the implications of the collective setting. We follow Browning (1999) for the individual cm-demands and model relative expenditures, i.e., the ratio of expenditures on the good to be modeled to expenditure on the conditioning good. The structure of individual cm-demands is as follows:

$$
\frac{\boldsymbol{m} \odot \boldsymbol{d}_{i}}{r_{i} x_{i}}=\boldsymbol{\Delta}_{i}+\frac{\boldsymbol{m} \odot \boldsymbol{f}_{i}}{r_{i} x_{i}}
$$

where $\odot$ stands for the Hadamard product, i.e., the element-by-element product, the function $\boldsymbol{\Delta}_{i}\left(r_{i}, x_{i}, \boldsymbol{m}, \boldsymbol{z}_{i}, \boldsymbol{z}\right)$ is the identifiable component of the individual cm-demands, and the function $\boldsymbol{f}_{i}(\boldsymbol{m}, \boldsymbol{z})$ is the non-identifiable component, as previously explained. Since $\boldsymbol{d}_{i}$ is not observed, the following transformation from individual to household demands is used:

$$
\frac{\boldsymbol{m} \odot \boldsymbol{D}}{\sum_{i} r_{i} x_{i}}=\frac{\sum_{i} r_{i} x_{i} \boldsymbol{\Delta}_{i}}{\sum_{i} r_{i} x_{i}},
$$

where the property $\sum_{i} \boldsymbol{f}_{i}=\mathbf{0}$ (in Proposition 3) is used. Thus, the non-identifiable component is eliminated. The role of the econometrician is then to select a functional form for the component $\boldsymbol{\Delta}_{i}$ of the cm-demands that can be identified.

After considerable experimentation, we adopted a variation of the AI Demand System. 
The functional form is the following:

$$
\boldsymbol{\Delta}_{i}=\boldsymbol{a}_{i}^{*}\left(\boldsymbol{z}_{i}, \boldsymbol{z}_{j}, \boldsymbol{z}\right)+\boldsymbol{B} \ln \boldsymbol{m}+\sum_{t=1}^{T} \boldsymbol{c}_{t}\left(\ln r_{i} x_{i}-\ln \Phi_{t}\right)^{t}+\boldsymbol{d} \ln r_{j} x_{j}
$$

with $j \neq i$, where $\boldsymbol{B}, \boldsymbol{c}_{t}$ and $\boldsymbol{d}$ are conformable vectors and matrices of parameters, $\boldsymbol{a}_{i}^{*}$ is a vector of functions and $\Phi_{t}$ are functions defined as follows:

$$
\ln \Phi_{1}=0 \quad \text { and } \quad \ln \Phi_{t}=\boldsymbol{c}_{t}^{\prime} \ln \boldsymbol{m} \text { if } t>1 .^{13}
$$

One advantage of this form is that the flexibility of the model can be arbitrarily increased by choosing a large $T$. However, it is advisable to be cautious and perform some simple empirical tests, because the levels and prices of the exclusive goods enter the functional form only through expenditures on them. Moreover, the individual demands are assumed, for the sake of parsimony, to have the same parameters (except for the intercepts, as is quite usual in econometrics). This assumption must also be carefully examined.

The next step is to make some allowance for observable heterogeneity and derive the theoretical constraints. To do this, we choose a functional form for the index $\boldsymbol{a}_{i}^{*}$ and allow for the fact that different people will have different tastes. A linear specification is adopted:

$$
\boldsymbol{a}_{i}^{*}\left(\boldsymbol{z}_{i}, \boldsymbol{z}_{j}, \boldsymbol{z}\right)=\boldsymbol{a}_{i}+\boldsymbol{a}_{1} \boldsymbol{z}_{i}+\boldsymbol{a}_{2} \boldsymbol{z}_{j}+\boldsymbol{a}_{3} \boldsymbol{z}
$$

where $\boldsymbol{a}_{i}, \boldsymbol{a}_{1}, \boldsymbol{a}_{2}$ and $\boldsymbol{a}_{3}$ are conformable vectors and matrices of parameters. The parameters of the functional forms (21) and (22) then have to satisfy several constraints for the model to be consistent with the theory. To derive these constraints, the vectors and matrices of parameters are first partitioned as follows:

$$
\boldsymbol{B}=\left(\begin{array}{ll}
\boldsymbol{B}^{11} & \boldsymbol{B}^{12} \\
\boldsymbol{B}^{21} & \boldsymbol{B}^{22}
\end{array}\right), \quad \boldsymbol{c}_{t}=\left(\begin{array}{c}
\boldsymbol{c}_{t}^{1} \\
\boldsymbol{c}_{t}^{2}
\end{array}\right), \quad \boldsymbol{d}=\left(\begin{array}{c}
\boldsymbol{d}^{1} \\
\boldsymbol{d}^{2}
\end{array}\right)
$$

\footnotetext{
${ }^{13}$ In the empirical application, a positive translation is applied to the level of the goods in right-hand side of expression (21) for the computation of the logarithms in the functional form. The reason is that, for some households, the observed expenditure on these goods is simply equal to zero during the period of observation.
} 
Table 1: List of constraints

\begin{tabular}{ll}
\hline \hline Name of constraints & Parameter restrictions \\
\hline Homogeneity & $\boldsymbol{B}^{11} \boldsymbol{\iota}+\boldsymbol{c}_{1}^{1}+\boldsymbol{d}^{1}=\mathbf{0}$, \\
& $\boldsymbol{B}^{21} \boldsymbol{\iota}+\boldsymbol{c}_{1}^{2}+\boldsymbol{d}^{2}=\mathbf{0}$, \\
& $\boldsymbol{c}_{t}^{1} \boldsymbol{\iota}=\boldsymbol{\iota}, t=2, \ldots, T$, \\
& with $\boldsymbol{\iota}=(1, \ldots, 1)^{\prime}$ \\
& $\boldsymbol{d}=\mathbf{0}$ \\
c-Separability & $\boldsymbol{B}^{\prime} \boldsymbol{B}^{\prime}$ \\
Symmetry & $\boldsymbol{a}_{2}=\mathbf{0}$ \\
p-Separability & $\boldsymbol{B}^{12}=\mathbf{0}$, \\
Separability of public goods & $\boldsymbol{c}_{t}^{2}=\mathbf{0}, t=1, \ldots, T$ \\
\hline \hline
\end{tabular}

where the dimension of $\boldsymbol{B}^{11}$ is $N_{1} \times N_{1}$, the dimension of $\boldsymbol{B}^{12}$ is $N_{1} \times N_{2}$, the dimension of $\boldsymbol{B}^{21}$ is $N_{2} \times N_{1}$ and so on. The constraints are summarized in Table 1 and most of them are quite intuitive. In particular, the derivation of the symmetry restriction is tedious ${ }^{14}$ but not difficult while the separability of public goods simply implies that the cm-demands for private goods do not depend on the quantity of public goods.

To complete this specification, we also have to introduce unobservable heterogeneity. The most satisfactory treatment would be to develop a fully stochastic model, but we adopt the more conventional approach of simply adding error terms to the aggregate demands:

$$
\frac{\boldsymbol{m} \odot \boldsymbol{D}}{\sum_{i} r_{i} x_{i}}=\frac{\sum_{i} r_{i} x_{i} \boldsymbol{\Delta}_{i}}{\sum_{i} r_{i} x_{i}}+\boldsymbol{\varepsilon},
$$

where $\varepsilon$ is a stochastic term. Potential sources of heterogeneity in the cm-context comes only from preferences and measurement/optimization errors. ${ }^{15}$

\footnotetext{
${ }^{14}$ See Appendix B for more information.

${ }^{15}$ The heterogeneity related to the intra-household distribution of bargaining power is directly summarized here by the level of the exclusive goods and does not enter the error terms.
} 
The quantity of exclusive and public goods are probably endogenous. The basic reason for this endogeneity is that the quantity of all goods are variables of choice and are simultaneously determined by unobservable members' tastes. To make things clearer, let us consider the example of 'clothing' - which can be seen as an exclusive good - and 'personal care services'. If some persons take particular care of their physical appearance and others do not, then the error term in the 'personal care services' equation is expected to be positively correlated with the regressor 'clothing'. This implies endogeneity. There is another important cause of endogeneity, though. In surveys, observations on expenditure are generally contaminated by the infrequency of purchases. These 'errors in variables' create another form of endogeneity.

The natural instruments for the quantity of exclusive goods are distribution factors, since the theory states that, conditional on the quantity of the exclusive goods, distribution factors should not affect the cm-demands. ${ }^{16}$ Then, a natural assumption which permits the econometric identification of the model is then the following:

$$
E\left(\boldsymbol{\varepsilon} \mid r_{A}, r_{B}, \boldsymbol{p}, \boldsymbol{P}, \boldsymbol{s}, \boldsymbol{z}_{A}, \boldsymbol{z}_{B}, \boldsymbol{z}\right)=0
$$

The exclusion of distribution factors from the cm-demands is, therefore, a theoretical prediction that can also be tested.

\section{Data and Results}

\subsection{The Consumer Expenditure Survey}

The data are drawn from the 'Interview' component of the 'Consumer Expenditure Survey'. This survey, which has been extensively used since the early eighties (see Nelson (1988), or Meghir and Weber (1996), for example), contains global estimates of total

\footnotetext{
${ }^{16}$ However, the household total expenditure $y$ is probably not a valid instrument, since it is also endogenously determined by household decisions.
} 
spending on food at home and other items for the three-month period immediately preceding the interview. It is a rotating panel. Households are interviewed five times, but the first quarter of expenditure data are used only for bounding purposes.

The complete sample includes about 100,000 households from 1980 to 1999. The data used in this study come from each of the overlapping 12-month periods January 1980December 1980, February 1980-January 1981, and so on through the 12 month period April 1998-March 1999. We then select a subsample of married couples without children, since children are expected to increase problems related to domestic production. We also restrict the sample to couples in which the husband and wife both work full-time (whose yearly labor supply falls between 1500 and 3000 hours) — otherwise, we should model labor supply decisions as well - and who are less than 65 years old. This is standard in the literature and, furthermore, reduces the heterogeneity of the sample. These selection rules and the exclusion of missing data ${ }^{17}$ leave us with a total of 2,604 cases for the empirical analysis. The construction of the sample is more precisely described in Appendix C.

We follow Browning et alii (1994) and suppose that 'men's clothing' (MCLO) and 'women's clothing' (WCLO) are exclusive goods. One notable (and especially important in the cm-context) feature of the Consumer Expenditure Survey is that, since expenditures are recorded over the year, there are far fewer zeros for goods such as clothing than one finds in surveys based on short diaries. We then model the demand for four private goods: 'food and beverages at home' (FDAH), 'food and beverages away from home' (REST), 'alcoholic beverages and tobacco' (VICE), 'personal care services' (CARE), and the demand for two public goods: 'oil fuel and utility natural gas service' (FUEL) and 'electricity, water and sewer and trash collection services' (UTIL). ${ }^{18}$ We assume that the

\footnotetext{
${ }^{17}$ The most important source of incomplete observations is attrition in the panel and the fact that the region of residence is not recorded for households living in rural areas. These observations are simply removed from our sample.

${ }^{18}$ Such a classification - even if it is always debatable in the end - seeks a broad consensus. Therefore, the classification of goods such as 'entertainment' or 'transportation' as public or private seems definitively too conjectural. A more ambitious line of attack consists in letting data determine the best classification
} 
preferences for these goods are separable from those for all other goods (allowing the exception of labor force status since we select full-time working members).

Prices ('Consumer Price Index for all urban consumers') are taken from the Bureau of Labor Statistics. The price of composite goods is created as the weighted geometric mean of the component prices with budget shares averaged across the sample for weights. Moreover, since the series are recorded over twenty years at the region level (North, South, West and Midwest), the variation in prices in our data is appreciable; see Appendix C. ${ }^{19}$

\subsection{Parameter Estimates and Test Statistics}

Before presenting estimates of the parameters, we have to address some econometric issues. The equations are estimated using conventional iterated GMM techniques to allow for the probable endogeneity of the conditioning goods. This estimation method is also consistent with heteroscedasticity of unknown form in the errors. The econometric tests are performed with LR-type tests. The corresponding statistics are computed as the difference between the J-statistics computed for the constrained and the unconstrained model; see Newey and West (1987). ${ }^{20}$

For the most general specification, and after numerous tests, we finally retained fifteen factors of preference in the $\boldsymbol{a}_{i}^{*}$ index. We take the age, the square of the age, the years of education for each spouse, and dummies for black households, Hispanic households ${ }^{21}$ and home owner households. We also include the logarithm of time and its square to allow for of goods. This is, however, beyond the scope of this paper.

${ }^{19}$ We use prices recorded at the country level for CARE (and for MCLO and WCLO and some components of VICE, FUEL, UTIL after January, 1998) since the regional information is not available.

${ }^{20}$ Following the common practice (Hayashi, 1998), we computed the J-statistics with the weighting matrix of the unconstrained model. We ascertained, however, that the tests are robust to the choice of other consistent weighting matrices.

${ }^{21}$ In principle, in cm-demands these variables can be considered specific factors of preferences. However, it is made difficult because there is a strong collinearity between the characteristics of the partners. That is, mixed marriages are rare. 
possible shifts in taste, and four dummies for the region of residence. ${ }^{22}$ As a preliminary, we decided that the optimal number of terms in expenditure, i.e., the value of $T$, must be equal to 2 . We will return to that later. Thus, we have twenty-five (free) parameters per equation for the most general model.

The usual technique for choosing instruments in GMM consists in selecting the order of a polynomial for the exogenous variables. The set of instruments in our application includes the logarithms of the prices of the public and private goods, a second-order polynomial in the logarithms of the prices of the exclusive goods, the socio-demographic variables used in the estimation process, a third-order polynomial in the logarithm of total income (composed of spouses' earnings and non-labor incomes), a second-order polynomial in the logarithms of the wife's and husband's earnings, and dummies for negative wife's and husband's earnings. ${ }^{23}$ Spouses' earnings and non-labor incomes can be seen here as distribution factors. In all, we have thirty-six instruments per equation. This gives eleven overidentifying restrictions per equation and a total of sixty-six degrees of freedom for the six-good system. The explanatory power and the possible endogeneity of these instruments have been extensively investigated, but we have not found any evidence of non-orthogonality or weakness.

To begin, we present the description of the different models we estimated and the corresponding set of J-statistics in Table 2. These models are nested and the different constraints are successively tested. The test of overidentifying restrictions for the unconstrained model indicates that the set of instruments, as a whole, is not rejected by the data at the usual levels. ${ }^{24}$ This means, in particular, that household demands, when con-

\footnotetext{
${ }^{22}$ To avoid collinearity between these variables and the individual constants, we assume that the sum of the parameters for the region dummies is equal to zero.

${ }^{23}$ The fact is that incomes may include loss from business and, therefore, may be negative. Thus, the logarithm of incomes is not computable for all observations, and the inverse hyperbolic sine of earnings and total income is actually used. This transformation is approximately logarithmic for high values of incomes and linear for values close to zero.

${ }^{24}$ The power of the overidentification test can be limited if the number of overidentifying restrictions
} 
Table 2: J-stats and tests of constraints

\begin{tabular}{lrcc}
\hline \hline The models and their characteristics & J-stats & D.F. & p-value \\
\hline Model I (unconstrained) & 74.30 & 66 & 0.23 \\
Model II (Model I + homogeneity) & 82.16 & 73 & 0.35 \\
Model III (Model II + c-separability) & 87.50 & 79 & 0.50 \\
Model IV (Model III + symmetry) & 104.54 & 94 & 0.32 \\
Model V (Model IV + p-separability) & 122.72 & 112 & 0.44 \\
Model VI (Model V + separability & & & \\
of public consumption) & 369.69 & 122 & 0.00 \\
\hline \hline
\end{tabular}

Notes: The first row of the last column indicates the p-value for the test of overidentification. The other rows indicate the p-value for the test of one model against the preceding one (e.g., the second row gives the p-value for the test of homogeneity and so on). 
ditioned on the quantity of two exclusive goods, are not influenced by the various incomes of the household. Moreover, the different sets of collective restrictions (homogeneity, cseparability, symmetry, p-separability) are not rejected at any conventional level. Thus, the data are consistent with the collective setting. ${ }^{25}$ However, the idea that preferences could be separable in public and private goods is much more unlikely. This assumption is definitively rejected and, of course, this casts doubts on the possibility of identifying individual cm-demands. Incidentally, the numerous empirical studies that are implicitly based on this assumption of separability could be seriously misleading. ${ }^{26}$

We now turn to the parameter estimates of the various models. To save on space, we focus more particularly on two specifications. In Table 3 we first present the estimates of Model II. That is, the estimated coefficients of the functional forms $\Delta_{i}$ when homogeneity is imposed. ${ }^{27}$ Remember that, except for the constants, these coefficients are the same for both members. The number of coefficients which are significant at the $5 \%$ (10\%) level is equal to 31 (35) out of 150 . Specifically, we must make two remarks here. First, the estimates of $\boldsymbol{d}$, in contrast with those of $\boldsymbol{c}_{1}$ and $\boldsymbol{c}_{2}$, are not significant at the $10 \%$ level. That confirms the formal test presented in Table 2. Second, the estimates of $\boldsymbol{B}$ are not very significant. Still, a careful examination of these estimates and their standard deviations reveals that the price-and-quantity effects are, as required by the theory, approximately symmetrical.

We next consider the estimates for Model $\mathrm{V}$ in Table 4. For this model, a greater proportion of parameters are precisely estimated: 39 (49) coefficients out of 132 are sigis high. However, the computation of J-statistics with subsets of instruments confirmed the hypothesis of exogeneity.

${ }^{25}$ We also tested c-separability in a more general model with a squared term in the expenditure of the partner. The conclusions are not altered.

${ }^{26}$ To the best of our knowledge, we here present the first empirical test — and the first rejection at the same time - of this type of separability at the household level.

${ }^{27}$ For the sake of efficiency, the estimation procedure for this model is based on the weighting matrix computed with the parameter estimates of Model V. As indicated in Table 2, this is the most constrained model not rejected by the data. 
Table 3: Estimates of the parameters for Model II

\begin{tabular}{|c|c|c|c|c|c|c|}
\hline \multirow[t]{2}{*}{ Parameters and labels } & \multicolumn{6}{|c|}{ Dependent variables $\left(\boldsymbol{m} \odot \boldsymbol{D} / \Sigma_{i} r_{i} x_{i}\right)$} \\
\hline & FDAH & REST & VICE & CARE & FUEL & UTIL \\
\hline \multirow[t]{2}{*}{$\mathrm{a}_{A}:$ intercept (men) } & 8.77 & 0.10 & 1.14 & 1.19 & -0.43 & -1.51 \\
\hline & $(2.96)$ & $(3.05)$ & $(1.53)$ & $(0.75)$ & $(0.55)$ & $(1.06)$ \\
\hline \multirow{2}{*}{$\mathrm{a}_{B}:$ intercept (women) } & 8.64 & -5.12 & 2.83 & -0.66 & 0.11 & -0.50 \\
\hline & $(1.85)$ & $(1.70)$ & $(0.99)$ & $(0.48)$ & $(0.36)$ & $(0.74)$ \\
\hline \multirow[t]{2}{*}{$a_{1}:$ North } & -0.30 & -0.05 & -0.13 & -0.04 & 0.01 & -0.01 \\
\hline & $(0.28)$ & $(0.32)$ & $(0.17)$ & $(0.08)$ & $(0.07)$ & $(0.09)$ \\
\hline \multirow[t]{2}{*}{$a_{1}$ : Midwest } & -0.25 & -0.01 & -0.05 & 0.01 & 0.10 & 0.05 \\
\hline & $(0.16)$ & $(0.17)$ & $(0.10)$ & $(0.04)$ & $(0.03)$ & $(0.05)$ \\
\hline \multirow[t]{2}{*}{$a_{1}$ : West } & 0.41 & 0.00 & 0.16 & 0.01 & -0.12 & 0.04 \\
\hline & $(0.31)$ & $(0.33)$ & $(0.19)$ & $(0.09)$ & $(0.07)$ & $(0.10)$ \\
\hline \multirow[t]{2}{*}{$a_{1}$ : South } & 0.13 & 0.06 & 0.02 & 0.01 & 0.012 & -0.08 \\
\hline & $(0.17)$ & $(0.18)$ & $(0.09)$ & $(0.04)$ & $(0.03)$ & $(0.06)$ \\
\hline \multirow[t]{2}{*}{$a_{1}$ : log. of a trend } & -0.79 & -0.43 & -0.43 & 0.02 & -0.25 & -0.23 \\
\hline & 0.39 & $(0.40)$ & $(0.24)$ & $(0.10)$ & $(0.09)$ & $(0.11)$ \\
\hline \multirow[t]{2}{*}{$a_{1}: \log$. of a trend $\exp 2$} & 0.32 & 0.16 & 0.15 & 0.01 & 0.10 & 0.09 \\
\hline & 0.13 & $(0.14)$ & $(0.08)$ & $(0.04)$ & $(0.03)$ & $(0.04)$ \\
\hline \multirow[t]{2}{*}{$a_{1}$ : black } & -0.28 & -0.76 & -0.32 & 0.17 & 0.03 & -0.13 \\
\hline & 0.20 & $(0.19)$ & $(0.10)$ & $(0.06)$ & $(0.04)$ & $(0.08)$ \\
\hline \multirow[t]{2}{*}{$a_{1}$ : Spanish-speaking } & -0.03 & -0.39 & -0.35 & -0.03 & -0.01 & 0.05 \\
\hline & 0.06 & $(0.22)$ & $(0.11)$ & $(0.06)$ & $(0.06)$ & $(0.07)$ \\
\hline \multirow[t]{2}{*}{$a_{1}$ : home owner } & 0.03 & -0.26 & 0.06 & 0.09 & 0.18 & 0.06 \\
\hline & 0.06 & $(0.63)$ & $(0.31)$ & $(0.16)$ & $(0.11)$ & $(0.20)$ \\
\hline \multirow[t]{2}{*}{$\mathrm{a}_{2}:$ education in decades } & 0.29 & -0.47 & -0.78 & -0.11 & 0.07 & 0.09 \\
\hline & $(0.59)$ & $(0.58)$ & $(0.51)$ & $(0.13)$ & $(0.10)$ & $(0.19)$ \\
\hline \multirow[t]{2}{*}{$\mathrm{a}_{2}$ : age } & -0.07 & -0.10 & -0.09 & -0.06 & 0.13 & -0.09 \\
\hline & $(0.25)$ & $(0.25)$ & $(0.14)$ & $(0.07)$ & $(0.05)$ & $(0.07)$ \\
\hline \multirow{2}{*}{$a_{2}:$ age in decades exp2 } & 0.15 & 0.11 & 0.09 & 0.07 & -0.15 & 0.11 \\
\hline & $(0.30)$ & $(0.30)$ & $(0.17)$ & $(0.08)$ & $(0.06)$ & $(0.09)$ \\
\hline \multirow{2}{*}{$\begin{array}{c}a_{3}: \text { education in decades } \\
\text { of the partner }\end{array}$} & -0.35 & 0.53 & 0.77 & 0.14 & -0.08 & -0.12 \\
\hline & $(0.54)$ & $(0.57)$ & $(0.50)$ & $(0.13)$ & $(0.10)$ & $(0.18)$ \\
\hline \multirow[t]{2}{*}{$\mathrm{a}_{3}:$ age of the partner } & 0.23 & 0.18 & 0.19 & 0.06 & -0.13 & 0.09 \\
\hline & $(0.26)$ & $(0.26)$ & $(0.15)$ & $(0.07)$ & $(0.05)$ & $(0.08)$ \\
\hline \multirow{2}{*}{$\begin{array}{l}\text { a3: age in decades of the } \\
\text { partner exp2 }\end{array}$} & -0.29 & -0.19 & -0.20 & -0.06 & 0.16 & -0.10 \\
\hline & $(0.30)$ & $(0.03)$ & $(0.17)$ & $(0.08)$ & $(0.06)$ & $(0.09)$ \\
\hline B: price of FDAH & 10.70 & -3.57 & 2.05 & 0.03 & 0.25 & -0.72 \\
\hline & $(3.78)$ & $(3.21)$ & $(1.64)$ & $(0.77)$ & $(0.64)$ & $(1.06)$ \\
\hline B: price of REST & -2.38 & 0.15 & -0.94 & 0.50 & -0.12 & -0.83 \\
\hline & $(3.26)$ & $(3.15)$ & $(1.85)$ & $(0.76)$ & $(0.74)$ & $(0.86)$ \\
\hline B: price of VICE & 0.47 & -1.56 & -1.13 & -0.28 & 0.02 & -0.63 \\
\hline & $(1.63)$ & $(1.56)$ & $(0.91)$ & $(0.37)$ & $(0.28)$ & $(0.49)$ \\
\hline B: price of CARE & -1.79 & 2.03 & 2.27 & -0.39 & -0.61 & 0.10 \\
\hline & $(2.97)$ & $(3.35)$ & $(2.03)$ & $(0.82)$ & $(0.91)$ & $(0.80)$ \\
\hline B: quantity of FUEL & 0.32 & 0.06 & 0.17 & -0.00 & -0.72 & 0.02 \\
\hline & $(0.65)$ & $(0.64)$ & $(0.35)$ & $(0.15)$ & $(0.13)$ & $(0.19)$ \\
\hline B: quantity of UTIL & -2.49 & 0.62 & -0.96 & -0.11 & 0.01 & -1.03 \\
\hline & $(0.99)$ & $(0.90)$ & $(0.49)$ & $(0.25)$ & $(0.20)$ & $(0.37)$ \\
\hline$c_{1}$ : expenditure on clothing & -5.30 & 3.24 & -1.41 & 0.15 & 0.14 & 2.42 \\
\hline & $(1.68)$ & $(1.56)$ & $(1.05)$ & $(0.42)$ & $(0.35)$ & $(0.61)$ \\
\hline $\mathrm{c}_{2}:$ expenditure on clothing & 1.23 & -0.65 & 0.44 & -0.03 & 0.02 & -0.24 \\
\hline $\exp 2$ & $(0.28)$ & $(0.25)$ & $(0.18)$ & $(0.07)$ & $(0.07)$ & $(0.09)$ \\
\hline d: expenditure on clothing & -1.71 & -0.29 & -0.84 & -0.00 & 0.33 & -0.34 \\
\hline of the partner & $(1.44)$ & $(1.44)$ & $(0.83)$ & $(0.36)$ & $(0.29)$ & $(0.41)$ \\
\hline
\end{tabular}

Notes: Standard deviations are in parentheses 
Table 4: Estimates of the parameters for Model V

\begin{tabular}{|c|c|c|c|c|c|c|}
\hline \multirow[t]{2}{*}{ Parameters and labels } & \multicolumn{6}{|c|}{ Dependent variables $\left(\boldsymbol{m} \odot \boldsymbol{D} / \Sigma_{i} r_{i} x_{i}\right)$} \\
\hline & FDAH & REST & VICE & CARE & FUEL & UTIL \\
\hline \multirow[t]{2}{*}{$\mathrm{a}_{A}:$ intercept (men) } & 6.43 & 2.25 & 1.18 & 1.71 & -0.36 & -1.96 \\
\hline & $(2.17)$ & $(1.84)$ & $(1.03)$ & $(0.54)$ & $(0.40)$ & $(0.88)$ \\
\hline \multirow[t]{2}{*}{$\mathrm{a}_{B}:$ intercept (women) } & 9.91 & -5.01 & 2.40 & -0.58 & 0.02 & -0.66 \\
\hline & $(1.65)$ & $(1.54)$ & $(0.86)$ & $(0.47)$ & $(0.35)$ & $(0.70)$ \\
\hline \multirow[t]{2}{*}{$a_{1}$ : North } & -0.02 & 0.02 & 0.06 & -0.01 & -0.01 & 0.03 \\
\hline & $(0.13)$ & $(0.12)$ & $(0.08)$ & $(0.04)$ & $(0.04)$ & $(0.04)$ \\
\hline \multirow[t]{2}{*}{$\mathrm{a}_{1}$ : Midwest } & -0.22 & 0.08 & 0.07 & 0.03 & 0.075 & 0.07 \\
\hline & $(0.10)$ & $(0.09)$ & $(0.06)$ & $(0.03)$ & $(0.03)$ & $(0.03)$ \\
\hline \multirow[t]{2}{*}{$a_{1}:$ West } & 0.10 & -0.04 & -0.12 & 0.00 & -0.08 & -0.05 \\
\hline & $(0.16)$ & $(0.14)$ & $(0.10)$ & $(0.05)$ & $(0.05)$ & $(0.06)$ \\
\hline \multirow[t]{2}{*}{$a_{1}$ : South } & 0.14 & -0.06 & -0.01 & -0.01 & 0.02 & -0.05 \\
\hline & $(0.10)$ & $(0.10)$ & $(0.05)$ & $(0.03)$ & $(0.03)$ & $(0.04)$ \\
\hline \multirow[t]{2}{*}{$a_{1}$ : log. of a trend } & -0.62 & -0.36 & -0.22 & 0.03 & -0.28 & -0.29 \\
\hline & $(0.32)$ & $(0.32)$ & $(0.20)$ & $(0.09)$ & $(0.08)$ & $(0.10)$ \\
\hline \multirow[t]{2}{*}{$a_{1}: \log$. of a trend exp2 } & 0.18 & 0.11 & 0.03 & 0.00 & 0.11 & 0.09 \\
\hline & $(0.10)$ & $(0.10)$ & $(0.06)$ & $(0.03)$ & $(0.02)$ & $(0.03)$ \\
\hline \multirow[t]{2}{*}{$a_{1}$ : black } & -0.02 & -0.70 & -0.27 & 0.17 & 0.03 & -0.07 \\
\hline & $(0.19)$ & $(0.15)$ & $(0.08)$ & $(0.06)$ & $(0.04)$ & $(0.07)$ \\
\hline \multirow[t]{2}{*}{$a_{1}$ : Spanish-speaking } & -0.10 & -0.44 & -0.36 & -0.04 & -0.03 & 0.07 \\
\hline & $(0.17)$ & $(0.19)$ & $(0.10)$ & $(0.05)$ & $(0.05)$ & $(0.06)$ \\
\hline \multirow[t]{2}{*}{$\mathrm{a}_{1}$ : home owner } & 0.09 & 0.23 & 0.05 & 0.17 & 0.15 & -0.01 \\
\hline & $(0.33)$ & $(0.29)$ & $(0.18)$ & $(0.11)$ & $(0.08)$ & $(0.16)$ \\
\hline \multirow[t]{2}{*}{$\mathrm{a}_{2}:$ education in decades } & -0.04 & 0.09 & 0.02 & 0.03 & -0.02 & -0.03 \\
\hline & $(0.04)$ & $(0.05)$ & $(0.03)$ & $(0.01)$ & $(0.01)$ & $(0.01)$ \\
\hline \multirow[t]{2}{*}{$\mathrm{a}_{2}$ : age } & 0.14 & 0.08 & 0.08 & 0.01 & -0.01 & 0.00 \\
\hline & $(0.03)$ & $(0.03)$ & $(0.02)$ & $(0.01)$ & $(0.01)$ & $(0.01)$ \\
\hline \multirow[t]{2}{*}{$\mathrm{a}_{2}:$ age in decades exp2 } & -0.12 & -0.07 & -0.09 & 0.01 & 0.01 & 0.00 \\
\hline & $(0.04)$ & $(0.04)$ & $(0.02)$ & $(0.01)$ & $(0.01)$ & $(0.01)$ \\
\hline \multirow{2}{*}{$\begin{array}{l}\mathrm{a}_{3}: \text { education in decades } \\
\text { of the partner }\end{array}$} & 0.00 & 0.00 & 0.00 & 0.00 & 0.00 & 0.00 \\
\hline & - & - & - & - & - & - \\
\hline \multirow{2}{*}{$a_{3}:$ age of the partner } & 0.00 & 0.00 & 0.00 & 0.00 & 0.00 & 0.00 \\
\hline & - & - & - & - & - & - \\
\hline \multirow{2}{*}{$\begin{array}{l}\mathrm{a}_{3}: \text { age in decades of the } \\
\text { partner exp2 }\end{array}$} & 0.00 & 0.00 & 0.00 & 0.00 & 0.00 & 0.00 \\
\hline & - & - & - & - & - & - \\
\hline B: price of FDAH & 8.38 & -3.38 & 1.82 & 0.06 & 0.05 & -1.63 \\
\hline & $(2.95)$ & $(1.87)$ & $(0.94)$ & $(0.57)$ & $(0.38)$ & $(0.75)$ \\
\hline B: price of REST & -3.38 & 0.19 & 0.13 & 0.28 & -0.24 & 0.09 \\
\hline & $(1.87)$ & $(1.46)$ & $(0.73)$ & $(0.49)$ & $(0.26)$ & $(0.48)$ \\
\hline $\mathrm{B}$ : price of VICE & 1.82 & 0.13 & -0.07 & 0.06 & -0.21 & -0.50 \\
\hline & $(0.94)$ & $(0.73)$ & $(0.57)$ & $(0.21)$ & $(0.16)$ & $(0.32)$ \\
\hline B: price of CARE & 0.06 & 0.28 & 0.06 & -0.41 & -0.08 & -0.23 \\
\hline & $(0.57)$ & $(0.49)$ & $(0.21)$ & $(0.51)$ & $(0.09)$ & $(0.19)$ \\
\hline B: quantity of FUEL & 0.05 & -0.24 & -0.21 & -0.08 & -0.65 & -0.02 \\
\hline & $(0.38)$ & $(0.26)$ & $(0.16)$ & $(0.09)$ & $(0.10)$ & $(0.13)$ \\
\hline B: quantity of UTIL & -1.63 & 0.09 & -0.50 & -0.23 & -0.02 & -0.74 \\
\hline & $(0.75)$ & $(0.48)$ & $(0.32)$ & $(0.19)$ & $(0.13)$ & $(0.35)$ \\
\hline$c_{1}$ : expenditure on clothing & -6.89 & 2.78 & -1.94 & 0.01 & 0.48 & 2.27 \\
\hline & $(1.07)$ & $(0.87)$ & $(0.56)$ & $(0.28)$ & $(0.25)$ & $(0.44)$ \\
\hline $\mathrm{c}_{2}$ : expenditure on clothing & 1.12 & -0.50 & 0.36 & 0.02 & 0.01 & -0.28 \\
\hline exp2 & $(0.24)$ & $(0.22)$ & $(0.15)$ & $(0.07)$ & $(0.06)$ & $(0.08)$ \\
\hline $\mathrm{d}$ : expenditure on clothing & 0.00 & 0.00 & 0.00 & 0.00 & 0.00 & 0.00 \\
\hline of the partner & - & - & - & - & - & - \\
\hline
\end{tabular}

Notes: Standard deviations are in parentheses 
nificant at the $5 \%(10 \%)$ level. In particular, the majority of the estimates of $\boldsymbol{c}_{1}$ and $\boldsymbol{c}_{2}$ are very significant (with t-tests higher than 2 in general). Still, the estimates of $\boldsymbol{B}$ remain imprecise: only 9 coefficients out of 36 are significant at the $10 \%$ level. This lack of precision can, of course, be explained by the strong collinearity in prices. Furthermore, the dependent variable here is the ratio of expenditures on one private/public good to expenditures on both exclusive goods. Also, the estimates of the parameters will not be very significant if the expenditures in the numerator and the denominator are strongly correlated. This may explain, in particular, why the estimates are generally not significant for the CARE equation.

As to the socio-demographic variables, we observe that racial and ethnic minorities have similar patterns of consumption for the REST and VICE equations. These patterns are more different for the CARE and UTIL equations. We also point out that more educated people spend relatively more on CARE and REST than on MCLO and WCLO and, quite surprisingly, home owners spend relatively less on FUEL. Finally, age is an important variable to explain the demands for FDAH, REST or VICE and the region dummies are, in general, not very significant.

Before turning to a more detailed investigation of these estimates, several empirical tests were conducted to check the adequacy of the present specification. Specifically, a third-order term in $\left(\ln r_{i} x_{i}-\Phi_{t}\right)$ was introduced into the functional form. However, the resulting decrease in the J-statistics turned out to be quite small — going from 122.72 to 119.21 - and the present specification is not rejected (the $\chi^{2}$ - statistic for this test is equal to 3.51 with a $\mathrm{p}$-value $=0.74$ ). It thus confirms our preliminary intuition that $T$ must be equal to 2 .

Other tests were performed. We checked whether the effect of the quantity of the exclusive goods and the effect of prices are distinct. We also examined the assumption that, except for constants, individual demands are the same for both members. All in all, the functional form that we adopted seems to conveniently fit the data. 
Table 5: Median of the distribution of the aggregate cm-demand elasticities computed from the estimates for Model V

\begin{tabular}{lccccccc}
\hline \hline & \multicolumn{3}{c}{ Elasticity of quantities } & Elasticity of \\
& & & \multicolumn{5}{c}{ prices } \\
\cline { 2 - 8 } & & & & & \\
& FDAH & REST & VICE & CARE & FUEL & UTIL \\
\hline Price of FDAH & 0.01 & -1.50 & 0.96 & 0.38 & 0.18 & 1.95 \\
& $(0.49)$ & $(0.95)$ & $(1.12)$ & $(0.94)$ & $(0.64)$ & $(0.96)$ \\
Price of REST & -0.69 & -4.40 & 1.90 & 2.05 & 0.96 & 1.24 \\
& $(0.44)$ & $(1.64)$ & $(1.32)$ & $(1.72)$ & $(0.65)$ & $(1.11)$ \\
Price of VICE & 0.17 & 0.64 & 0.75 & -0.40 & 0.75 & 0.85 \\
& $(0.19)$ & $(0.45)$ & $(1.17)$ & $(0.64)$ & $(0.33)$ & $(0.62)$ \\
Price of CARE & 0.03 & 0.39 & -0.23 & -0.01 & -0.48 & -0.31 \\
& $(0.08)$ & $(0.33)$ & $(0.36)$ & $(1.22)$ & $(0.18)$ & $(0.21)$ \\
Quantity of FUEL & -0.02 & -0.25 & -0.57 & 0.64 & -1.10 & 0.12 \\
& $(0.07)$ & $(0.17)$ & $(0.25)$ & $(0.24)$ & $(0.51)$ & $(0.23)$ \\
Quantity of UTIL & -0.26 & -0.30 & -0.63 & 0.53 & 0.12 & 1.09 \\
& $(0.12)$ & $(0.29)$ & $(0.47)$ & $(0.37)$ & $(0.23)$ & $(0.85)$ \\
Expenditure & 0.17 & 2.35 & 0.15 & 0.28 & 0.22 & 0.11 \\
on men's clothing & $(0.03)$ & $(0.48)$ & $(0.14)$ & $(0.09)$ & $(0.05)$ & $(0.03)$ \\
Expenditure & 0.35 & -0.54 & 0.32 & 0.44 & 0.05 & 0.06 \\
$\quad$ on women's clothing & $(0.16)$ & $(0.41)$ & $(0.22)$ & $(0.14)$ & $(0.12)$ & $(0.11)$ \\
\hline \hline
\end{tabular}

Notes: Standard deviations (computed by bootstrap) are in parentheses.

\subsection{Elasticities and Identification}

As previously shown, the separability of the public goods from the other goods is clearly rejected by our data. Consequently the complete identification of the individual cmdemands is not possible. Still, some interesting information on the decision process can be obtained. We first checked, using equation (14), that the income elasticities for the exclusive goods are positive for the large majority of observations (all the income-elasticities for men computed from the sample are positive, and less than $5 \%$ of these elasticities for women are negative) and concluded that these goods are (conditionally) normal, as required by A1.

We next turned to the computation of the elasticities of the cm-demands but, as a preliminary, we checked the equality of the individual intercepts, $\boldsymbol{a}_{A}=\boldsymbol{a}_{B}$, for each 
equation. It turns out that only the intercepts for REST are significantly different from each other. We therefore imposed the conditions $\boldsymbol{a}_{A}=\boldsymbol{a}_{B}$ for all goods except REST — this is restrictive but greatly increases the precision of the estimates - and we computed, for each observation, the price-and-quantity and expenditure elasticities from the parameter estimates of the constrained model. The median of the distribution of these elasticities is given in Table 5.

One remark is in order to interpret this table. If A1 is fulfilled, the quantity of exclusive goods is a valid indicator of the individual consumption of exclusive and private goods in general. Thus, a rise in men's and women's clothing expenditure should increase the demand for any normal private good. Broadly speaking, the conclusion is the same for public goods: a rise in men's and women's clothing expenditure should be associated with an increase in the price of any normal public good (provided that the quantity of the corresponding public good is kept constant). ${ }^{28}$ In this context, the first conclusion we can draw is that the majority of goods are normal. The only exception is the demand for REST by women, but it is not very significant. To make up for that, the elasticity of the demand for REST by men is positive and very large. More precisely, from A2 and Corollary 4, an increase of the bargaining power of the husband can be shown to imply an increase in the quantity of REST demanded by the household as a whole. Similarly, an increase in the bargaining power of the husband can be shown to imply an increase in the quantity of FUEL and UTIL demanded by the household, and a decrease in the quantity of FDAH, VICE and CARE. Such a result, linking the intra-household distribution of power to the demand for public goods, has never been seen in the literature.

The second notable point is that the price-and-quantity elasticities are now fairly well estimated: 19 parameters out of 36 are significant at the $20 \%$ level. The own price-andquantity elasticities for REST and FUEL are significant and have the expected sign (even if the theory does not predict the negativity of the own price-and-quantity effects). The

\footnotetext{
${ }^{28}$ Note that the definitions of normality at stake here, even if quite intuitive, do not exactly coincide with the traditional definitions found in microeconomics.
} 
other own price-and-quantity elasticities are not significant.

\section{Conclusion}

One of the main topical themes of research in collective models concerns the treatment of public consumption. Our objective was to develop and estimate a collective model of household behavior with public and private goods.

In a few words, our main results can be summarized as follows. First, we propose what we call a 'cm-demand' framework, in which household demands are directly derived from the marginal rates of substitution. This framework, which turns out to be especially profitable for investigating the properties of collective demands, is extensively exploited in this paper. Second, we show, using this framework, that household demands for public and private goods have to satisfy testable constraints and that some elements of the decision process can be retrieved from observed behavior. Moreover, the identification is complete if preferences are assumed to be such that public and private goods are separable. We also define the new concepts of 'specific' and 'common' factors of preferences. Third, we implement this theoretical model and present empirical results with U.S. data. It turns out that, overall, the data are consistent with the theoretical model. This contribution is appreciable because, in fact, collective models of demand accounting for variable prices are rarely estimated.

We also present the first test, to the best of our knowledge, of the separability of public and private consumption in preferences. The evidence strongly suggests that such a separability is rejected. It makes one wonder, then, how individual demands could be retrieved in a collective model with public and private goods. One solution is to follow Couprie (2003) and Browning, Chiappori and Lewbel (2004), and assume that the preferences of single and married persons are indistinguishable. This line of attack, even if less general than the approach adopted in the paper, certainly deserves more attention.

To conclude this paper, we should like to suggest two promising directions for future 
research. First, in the present paper, we assume that all goods are pure, either private or public. However, more realistically, most goods in households should certainly be regarded as impure. For example, expenditures on 'telephone services' include the rental as a public element and the actual use of telephone as a private element. Nevertheless, identification of the structural model undoubtedly raises further difficulties in this case. Yet, these difficulties are not insurmountable, as was shown by Fong and Zhang (2001) in a labor supply context, but more structure is probably necessary here. Second, we assume that all goods are non-durable. However, most public goods in households are to some extent durable. This is obvious when you think to lodging or appliances. Thus, the theory should be expanded to cover the case of durable goods.

\section{Appendix A : List of Proofs}

\section{Proof of Proposition 1}

$1 \& 2$. The homogeneity of the individual cm-demands results from the first order conditions (7) and (10). The homogeneity of the aggregate cm-demands follows.

\section{Proof of Proposition 2}

1. The first statement in Proposition 2 is trivial and the proof is straightforward. We thus turn to the second statement.

2. Let us consider the (conditional) compensated demands and prices for each household member. They are defined in the usual way as follows:

$$
x_{i}=x_{i}^{c}\left(r_{i}, \boldsymbol{m}, u_{i}\right), \quad \boldsymbol{q}_{i}=\boldsymbol{q}_{i}^{c}\left(r_{i}, \boldsymbol{m}, u_{i}\right), \quad \boldsymbol{p}_{i}=\boldsymbol{p}_{i}^{c}\left(r_{i}, \boldsymbol{m}, u_{i}\right) .
$$


The latter term is a virtual price as in Neary and Roberts (1980). Then, a result by Madden (1991, Lemma 1) indicates that the matrix

$$
\left[\begin{array}{ccc}
\frac{\partial x_{i}^{c}}{\partial r_{i}} & \frac{\partial x_{i}^{c}}{\partial \boldsymbol{p}^{\prime}} & \frac{\partial x_{i}^{c}}{\partial \boldsymbol{q}^{\prime}} \\
\frac{\partial \boldsymbol{q}_{i}^{c}}{\partial r_{i}} & \frac{\partial \boldsymbol{q}_{i}^{c}}{\partial \boldsymbol{p}^{\prime}} & \frac{\partial \boldsymbol{q}_{i}^{c}}{\partial \boldsymbol{q}^{\prime}} \\
-\frac{\partial \boldsymbol{p}_{i}^{c}}{\partial r_{i}} & -\frac{\partial \boldsymbol{p}_{i}^{c}}{\partial \boldsymbol{p}^{\prime}} & -\frac{\partial \boldsymbol{p}_{i}^{c}}{\partial \boldsymbol{q}^{\prime}}
\end{array}\right]
$$

is symmetrical. The next step is to show that this result directly implies the symmetry of individual cm-demands.

Lemma 7 Under collective rationality with egoistic agents and A1,

$$
\left(\frac{\partial \boldsymbol{d}_{i}}{\partial \boldsymbol{m}^{\prime}}+\frac{\partial \boldsymbol{d}_{i}}{\partial x_{i}} \frac{\partial \boldsymbol{d}_{i}^{\prime}}{\partial r_{i}}\right) \text { is symmetrical. }
$$

Proof. We simply generalize here the argument of Browning (1999). First, the inversion of $x_{i}^{c}\left(r_{i}, \boldsymbol{m}, u_{i}\right)$ yields:

$$
x_{i}=x_{i}^{c}\left(r_{i}, \boldsymbol{m}, u_{i}\right) \Leftrightarrow u_{i}=\psi_{i}\left(r_{i}, \boldsymbol{m}, x_{i}\right) .
$$

The inversion is possible if A1 is assumed. The function $\psi_{i}\left(r_{i}, \boldsymbol{m}, x_{i}\right)$ has some properties of a preference representation but it is not a valid representation in the sense that there is a one-to-one mapping from preferences to these functions. We have, naturally, the following identity:

$$
x_{i} \equiv x_{i}^{c}\left[r_{i}, \boldsymbol{m}, \psi_{i}\left(r_{i}, \boldsymbol{m}, x_{i}\right)\right] .
$$

Since this holds identically, we can differentiate with respect to $x_{i}, \boldsymbol{m}$ and $r_{i}$ :

$$
\begin{aligned}
\frac{\partial x_{i}^{c}}{\partial u_{i}} \frac{\partial \psi_{i}}{\partial x_{i}} & =1 \\
\frac{\partial x_{i}^{c}}{\partial \boldsymbol{m}}+\frac{\partial x_{i}^{c}}{\partial u_{i}} \frac{\partial \psi_{i}}{\partial \boldsymbol{m}} & =0 \\
\frac{\partial x_{i}^{c}}{\partial r_{i}}+\frac{\partial x_{i}^{c}}{\partial u_{i}} \frac{\partial \psi_{i}}{\partial r_{i}} & =0 .
\end{aligned}
$$


On the other hand, the individual cm-demands are defined by:

$$
\boldsymbol{d}_{i}=\boldsymbol{d}_{i}^{c}\left[r_{i}, \boldsymbol{m}, \psi_{i}\left(r_{i}, \boldsymbol{m}, x_{i}\right)\right]
$$

where $\left(\boldsymbol{d}_{i}^{c}\right)^{\prime}=\left[\left(\boldsymbol{q}_{i}^{c}\right)^{\prime},-\left(\boldsymbol{p}_{i}^{c}\right)^{\prime}\right]$. This procedure is very close to Cook's method for deriving Marshallian demands from the cost function. Taking the derivatives and substituting from equations (25)-(27), we have:

$$
\begin{aligned}
\frac{\partial \boldsymbol{d}_{i}}{\partial x_{i}} & =\frac{\partial \boldsymbol{d}_{i}^{c}}{\partial u_{i}} \frac{\partial \psi_{i}}{\partial x_{i}}=\frac{\partial \boldsymbol{d}_{i}^{c}}{\partial u_{i}}\left(\frac{\partial x_{i}^{c}}{\partial u_{i}}\right)^{-1}, \\
\frac{\partial \boldsymbol{d}_{i}}{\partial r_{i}} & =\frac{\partial \boldsymbol{d}_{i}^{c}}{\partial r_{i}}+\frac{\partial \boldsymbol{d}_{i}^{c}}{\partial u_{i}} \frac{\partial \psi_{i}}{\partial r_{i}}=\frac{\partial \boldsymbol{d}_{i}^{c}}{\partial r_{i}}-\frac{\partial \boldsymbol{d}_{i}^{c}}{\partial u_{i}} \frac{\partial x_{i}^{c}}{\partial r_{i}}\left(\frac{\partial x_{i}^{c}}{\partial u_{i}}\right)^{-1}, \\
\frac{\partial \boldsymbol{d}_{i}}{\partial \boldsymbol{m}^{\prime}} & =\frac{\partial \boldsymbol{d}_{i}^{c}}{\partial \boldsymbol{m}^{\prime}}+\frac{\partial \boldsymbol{d}_{i}^{c}}{\partial u_{i}} \frac{\partial \psi_{i}}{\partial \boldsymbol{m}^{\prime}}=\frac{\partial \boldsymbol{d}_{i}^{c}}{\partial \boldsymbol{m}^{\prime}}-\frac{\partial \boldsymbol{d}_{i}^{c}}{\partial u_{i}} \frac{\partial x_{i}^{c}}{\partial \boldsymbol{m}^{\prime}}\left(\frac{\partial x_{i}^{c}}{\partial u_{i}}\right)^{-1} .
\end{aligned}
$$

Using $\partial x_{i}^{c} / \partial \boldsymbol{m}=\partial \boldsymbol{d}_{i}^{c} / \partial r_{i}$ (by the symmetry of matrix (24)) and rearranging, we obtain:

$$
\frac{\partial \boldsymbol{d}_{i}}{\partial \boldsymbol{m}^{\prime}}+\frac{\partial \boldsymbol{d}_{i}}{\partial x_{i}} \frac{\partial \boldsymbol{d}_{i}^{\prime}}{\partial r_{i}}=\frac{\partial \boldsymbol{d}_{i}^{c}}{\partial \boldsymbol{m}^{\prime}}+\frac{\partial \boldsymbol{d}_{i}}{\partial x_{i}} \frac{\partial \boldsymbol{d}_{i}^{\prime}}{\partial x_{i}} \frac{\partial x_{i}^{c}}{\partial r_{i}} .
$$

Since the right-hand side is symmetric, so is the left-hand side.||

Since $\boldsymbol{D}=\sum_{i} \boldsymbol{d}_{i}, \partial \boldsymbol{d}_{i} / \partial x_{i}=\partial \boldsymbol{D} / \partial x_{i}$ and $\partial \boldsymbol{d}_{i} / \partial r_{i}=\partial \boldsymbol{D}_{i} / \partial r_{i}$, the proof of the second statement in Proposition 2 follows from Lemma 7.

\section{Proof of Proposition 3}

$1 \& 2$. The proof of the first and the second statement is straightforward. The derivatives of the individual demands for private goods can be retrieved and we have:

$$
\frac{\partial \boldsymbol{q}_{i}}{\partial r_{i}}=\frac{\partial \boldsymbol{Q}}{\partial r_{i}} \quad \text { and } \quad \frac{\partial \boldsymbol{q}_{i}}{\partial x_{i}}=\frac{\partial \boldsymbol{Q}}{\partial x_{i}},
$$

where the right-hand side of these expressions is known. The derivatives of the individual prices for public goods can be retrieved as well. We have:

$$
\frac{\partial \boldsymbol{p}_{i}}{\partial r_{i}}=\frac{\partial \boldsymbol{P}}{\partial r_{i}} \quad \text { and } \quad \frac{\partial \boldsymbol{p}_{i}}{\partial x_{i}}=\frac{\partial \boldsymbol{P}}{\partial x_{i}}
$$

Since the derivatives of $\boldsymbol{D}$ with respect to $\boldsymbol{p}$ and $\boldsymbol{q}$ are not identified, the individual cmdemands are identified up to a function $\boldsymbol{f}_{i}(\boldsymbol{p}, \boldsymbol{q})$. That is, $\boldsymbol{d}_{i}=\hat{\boldsymbol{d}}_{i}+\boldsymbol{f}_{i}$ where $\hat{\boldsymbol{d}}_{i}$ is a 
particular solution of the system of partial differential equations (28) and (29), and $\boldsymbol{d}_{i}$ is the general solution.

3. We now turn to the proof of the third statement. We know from the preceding that $\sum_{i}\left(\hat{\boldsymbol{d}}_{i}+\boldsymbol{f}_{i}\right)=\boldsymbol{D}$ where $\boldsymbol{D}$ is known. Since any particular solution must also satisfy $\sum_{i} \hat{\boldsymbol{d}}_{i}=\boldsymbol{D}$, we have $\sum_{i} \boldsymbol{f}_{i}=\mathbf{0}$. Similarly, as indicated by the first-order conditions (7) and (10), any particular solution has to satisfy the homogeneity restriction:

$$
\frac{\partial \hat{\boldsymbol{q}}_{i}}{\partial \boldsymbol{p}^{\prime}} \boldsymbol{p}+\frac{\partial \hat{\boldsymbol{q}}_{i}}{\partial r_{i}} r_{i}=0 \quad \text { and } \quad \frac{\partial \hat{\boldsymbol{p}}_{i}}{\partial \boldsymbol{p}^{\prime}} \boldsymbol{p}+\frac{\partial \hat{\boldsymbol{p}}_{i}}{\partial r_{i}} r_{i}=-\hat{\boldsymbol{p}}_{i}
$$

and, consequently, $\boldsymbol{g}_{i}$ is homogeneous of degree zero in $\boldsymbol{p}$ and $\boldsymbol{h}_{i}$ is homogeneous of degree one in $\boldsymbol{p}$. Finally, from Lemma 7, any particular solution has to satisfy the symmetry restriction:

$$
\frac{\partial \hat{\boldsymbol{d}}_{i}}{\partial \boldsymbol{m}^{\prime}}+\frac{\partial \hat{\boldsymbol{d}}_{i}}{\partial x_{i}} \frac{\partial \hat{\boldsymbol{d}}_{i}^{\prime}}{\partial r_{i}}=\frac{\partial \hat{\boldsymbol{d}}_{i}^{\prime}}{\partial \boldsymbol{m}}+\frac{\partial \hat{\boldsymbol{d}}_{i}}{\partial r_{i}} \frac{\partial \hat{\boldsymbol{d}}_{i}^{\prime}}{\partial x_{i}}
$$

and, consequently, $\boldsymbol{f}_{i}$ is symmetrical.

\section{Proof of Corollary 4}

If we differentiate the cm-demands with respect to $x_{A}, x_{B}, \boldsymbol{q}, \boldsymbol{Q}$, we obtain:

$$
\begin{aligned}
\mathrm{d} \boldsymbol{Q} & =\frac{\partial \boldsymbol{Q}}{\partial \boldsymbol{q}^{\prime}} \cdot \mathrm{d} \boldsymbol{q}+\frac{\partial \boldsymbol{Q}}{\partial x_{A}} \cdot \mathrm{d} x_{A}+\frac{\partial \boldsymbol{Q}}{\partial x_{B}} \cdot \mathrm{d} x_{B}, \\
-\mathrm{d} \boldsymbol{q} & =\left(\frac{\partial \boldsymbol{P}}{\partial \boldsymbol{q}^{\prime}}\right)^{-1}\left(\frac{\partial \boldsymbol{P}}{\partial x_{A}} \cdot \mathrm{d} x_{A}+\frac{\partial \boldsymbol{P}}{\partial x_{B}} \cdot \mathrm{d} x_{B}\right) .
\end{aligned}
$$

The second line describes the effect of an increase in the quantity of the exclusive goods on the quantity of public goods. Now, we consider a simultaneous variation in $x_{A}$ and in $x_{B}$ such that the total expenditure, and prices remain the same, i.e.,

$$
\sum_{i}\left(r_{i}+\left.\boldsymbol{p}^{\prime} \frac{\partial \boldsymbol{Q}}{\partial x_{i}}\right|_{\mathrm{d} \boldsymbol{P}=\mathbf{0}}+\left.\boldsymbol{P}^{\prime} \frac{\partial \boldsymbol{q}}{\partial x_{i}}\right|_{\mathrm{d} \boldsymbol{P}=\mathbf{0}}\right) \cdot \mathrm{d} x_{i}=0
$$

Using equations (30) and (31), this yields:

$$
\Psi_{A} \cdot \mathrm{d} x_{A}+\Psi_{B} \cdot \mathrm{d} x_{B}=0
$$


where

$$
\Psi_{i}=\left(r_{i}-\boldsymbol{p}^{\prime}\left(\frac{\partial \boldsymbol{Q}}{\partial \boldsymbol{q}^{\prime}}\left(\frac{\partial \boldsymbol{P}}{\partial \boldsymbol{q}^{\prime}}\right)^{-1}\left(\frac{\partial \boldsymbol{P}}{\partial x_{i}}\right)+\frac{\partial \boldsymbol{Q}}{\partial x_{i}}\right)-\boldsymbol{P}^{\prime}\left(\frac{\partial \boldsymbol{P}}{\partial \boldsymbol{q}^{\prime}}\right)^{-1} \frac{\partial \boldsymbol{P}}{\partial x_{i}}\right)
$$

From A2, we have: $\Psi_{i} \neq 0$. Now, rearranging these expressions yields:

$$
\begin{aligned}
\mathrm{d} \boldsymbol{Q} & =\left(\frac{\partial \boldsymbol{Q}}{\partial x_{A}}-\frac{\partial \boldsymbol{Q}}{\partial x_{B}} \frac{\boldsymbol{\Psi}_{A}}{\Psi_{B}}-\frac{\partial \boldsymbol{Q}}{\partial \boldsymbol{q}^{\prime}}\left(\frac{\partial \boldsymbol{P}}{\partial \boldsymbol{q}^{\prime}}\right)^{-1}\left(\frac{\partial \boldsymbol{P}}{\partial x_{A}}-\frac{\partial \boldsymbol{P}}{\partial x_{B}} \frac{\Psi_{A}}{\Psi_{B}}\right)\right) \mathrm{d} x_{A}, \\
\mathrm{~d} \boldsymbol{q} & =-\left(\frac{\partial \boldsymbol{P}}{\partial \boldsymbol{q}^{\prime}}\right)^{-1}\left(\frac{\partial \boldsymbol{P}}{\partial x_{A}}-\frac{\partial \boldsymbol{P}}{\partial x_{B}} \frac{\Psi_{A}}{\Psi_{B}}\right) \mathrm{d} x_{A} .
\end{aligned}
$$

The right-hand side can be evaluated from the estimation of cm-demands. That means that, according to A2, the sign of the effect of a variation in the bargaining power on the quantity of private and public goods is defined.

\section{Proof of Proposition 5}

The proof is straightforward from the additive (19) of the 'extended' cm-demands.

\section{Proof of Proposition 6}

1. The first statement of Proposition 6 is trivial. Since separability implies that:

$$
\frac{\partial \boldsymbol{q}_{i}}{\partial \boldsymbol{q}^{\prime}}=0
$$

the individual $\mathrm{cm}$-demands for private goods are identified up to a function $\boldsymbol{g}_{i}(\boldsymbol{p})$, which is independent of $\boldsymbol{q}$.

2. We now turn to the second statement. Using (32) and Lemma 7, symmetry (at the individual level) implies that:

$$
\frac{\partial \boldsymbol{p}_{i}}{\partial \boldsymbol{p}^{\prime}}=\frac{\partial \boldsymbol{p}_{i}}{\partial r_{i}} \frac{\partial \boldsymbol{q}_{i}^{\prime}}{\partial x_{i}}-\frac{\partial \boldsymbol{p}_{i}}{\partial x_{i}} \frac{\partial \boldsymbol{q}_{i}^{\prime}}{\partial r_{i}}
$$

On the other hand, homogeneity (at the individual level) implies:

$$
\boldsymbol{p}_{i}=\frac{\partial \boldsymbol{p}_{i}}{\partial \boldsymbol{p}^{\prime}} \boldsymbol{p}+\frac{\partial \boldsymbol{p}_{i}}{\partial r_{i}} r_{i}
$$


Substituting (33) and using Proposition 3 yield:

$$
\boldsymbol{p}_{i}=\left(\frac{\partial \boldsymbol{P}}{\partial r_{i}} \frac{\partial \boldsymbol{Q}^{\prime}}{\partial x_{i}}-\frac{\partial \boldsymbol{P}}{\partial x_{i}} \frac{\partial \boldsymbol{Q}^{\prime}}{\partial r_{i}}\right) \boldsymbol{p}+\frac{\partial \boldsymbol{P}}{\partial r_{i}} r_{i}
$$

The individual cm-demands are then exactly identified.

3. Finally, we consider the third statement: the separability of public goods generates additional constraints. First, the cm-demands for private goods are independent of the quantity of public goods, as shown by equation (32). Second, the individual cm-demands for public goods must satisfy cm-symmetry at the individual level. To conclude, note that there are other constraints but these are more complicated to demonstrate.

\section{Appendix B : Parametric Implications of Symmetry}

To derive the conditions on parameters that symmetry implies, we consider the individual $\mathrm{cm}$-demands in the case where $t=2$. For good $k$, we have:

$$
\begin{aligned}
d_{k} & =\frac{r_{i} x_{i}}{m_{k}} \times \Delta \\
& =\frac{r_{i} x_{i}}{m_{k}} \times\left[a_{i k}^{*}+\boldsymbol{b}_{k} \ln \boldsymbol{m}+c_{k 1} \ln r_{i} x_{i}+c_{k 2}\left(\ln r_{i} x_{i}-\ln \Phi_{2}\right)\right]
\end{aligned}
$$

where $a_{i k}^{*}, c_{k 1}, c_{k 2}$ are, respectively, the $k$ th element of $\boldsymbol{a}_{i}^{*}, \boldsymbol{c}_{1}$ and $\boldsymbol{c}_{2}$ and $\boldsymbol{b}_{k}$ is the $k$ th row of $\boldsymbol{B}$. Now, if we compute the $(k, l)$ th element of the symmetric matrix, we obtain:

$$
\begin{aligned}
\frac{\partial d_{i k}}{\partial m_{l}}+\frac{\partial d_{i k}}{\partial x_{i}} \frac{\partial d_{i l}}{\partial r_{i}}= & \frac{r_{i} x_{i}}{m_{k} m_{l}} \times\left(b_{k l}-\frac{c_{k 2} c_{l 2}}{\Phi_{2}}\right) \\
& +\left[\frac{r_{i}}{m_{k}} \times\left(\Delta+c_{k 1}+c_{k 2}\right)\right] \times\left[\frac{x_{i}}{m_{l}} \times\left(\Delta+c_{l 1}+c_{l 2}\right)\right] .
\end{aligned}
$$

Clearly, this expression is equal to the $(l, k)$ th element if $b_{k l}=b_{l k}$. If this condition is satisfied, the aggregate demands $\boldsymbol{D}$ will satisfy the symmetry condition. 


\section{Appendix C : Construction of the Data}

The order in which the selection criteria were applied, and their effects in terms of the number of observations deleted using each criteria, is given in Table B1. The number of candidate observations (which could theoretically be used in the estimation process) is equal to 32,346 . The most important selection is due to the deletion of households with children. The number of incomplete observations is small, since the missing values in instruments were imputed by their sample means. These incomplete observations include mainly rural households because, for confidentiality reasons, the region of residence of these households is not known. The descriptive statistics of the sample are given in Table $\mathrm{B} 2$.

Table B1: Selection Criteria of the Sample

\begin{tabular}{lrr}
\hline \hline Total number of observations & 96,949 \\
Attrition in the family survey & - & 35,258 \\
Single headed households & - & 29,345 \\
\hline Total number of candidate observations & - & 32,346 \\
\hline Households with members $>$ 65 years & - & 18,396 \\
Household with children & - & 4,703 \\
Households with part-time (or non) working members & - & 282 \\
\hline Incomplete observations (rural households \& topcoding) & & 2,604 \\
\hline Remaining sample
\end{tabular}

Notes: Topcoding refers to the replacement of data, for confidentiality reasons, when the absolute value of the original data exceeds the allowable limits. 
Table B2: Descriptive Statistics of the Sample

\begin{tabular}{|c|c|c|}
\hline & Mean & St.D. \\
\hline \multicolumn{3}{|l|}{ Quantities (expenditure/prices) } \\
\hline Men's clothing & 3.137 & 3.792 \\
\hline Women's clothing & 5.183 & 5.895 \\
\hline Food and beverages at home & 23.794 & 9.680 \\
\hline Food and beverages away from home & 13.238 & 12.273 \\
\hline Alcoholic beverages and tobacco & 5.052 & 5.340 \\
\hline Personal care services & 2.411 & 1.840 \\
\hline Oil fuel and utility natural gas service & 4.366 & 4.190 \\
\hline $\begin{array}{l}\text { Electricity, water and sewer } \\
\text { and trash collection services }\end{array}$ & 9.048 & 4.790 \\
\hline \multicolumn{3}{|l|}{ Prices (base 1980-1984=100) } \\
\hline Men's clothing & 117.099 & 13.352 \\
\hline Women's clothing & 118.036 & 15.209 \\
\hline Food and beverages at home & 127.353 & 21.542 \\
\hline Food and beverages away from home & 129.042 & 21.782 \\
\hline Alcoholic beverages and tobacco & 147.401 & 37.491 \\
\hline Personal care services & 129.950 & 23.088 \\
\hline Oil fuel and utility natural gas service & 99.437 & 9.561 \\
\hline $\begin{array}{l}\text { Electricity, water and sewer } \\
\text { and trash collection services }\end{array}$ & 119.576 & 16.742 \\
\hline \multicolumn{3}{|l|}{ Socio-demographic variables } \\
\hline Husband's education in years & 17.656 & 11.316 \\
\hline Wife's education in years & 17.858 & 11.106 \\
\hline Husband's age in years & 43.267 & 12.077 \\
\hline Wife's age in years & 40.925 & 11.751 \\
\hline Proportion of black households & 0.048 & 0.213 \\
\hline Proportion of Hispanic households & 0.033 & 0.180 \\
\hline Proportion of North residents & 0.217 & 0.413 \\
\hline Proportion of South residents & 0.303 & 0.460 \\
\hline Proportion of Midwest residents & 0.264 & 0.441 \\
\hline Proportion of West residents & 0.215 & 0.411 \\
\hline
\end{tabular}




\section{References}

[1] Altonji Joseph G., 1986, "Intertemporal Substitution in Labor Supply: Evidence from Micro Data", Journal of Political Economy 94: S176-S215.

[2] Becker Gary S., 1991, A Treatise on the Family. Enlarged Edition. Cambridge, Mass. : Harvard University Press.

[3] Bourguignon François, Martin Browning, Pierre-André Chiappori and Valérie Lechene, 1993, "Intra Household Allocation of Consumption: A Model and Some Evidence from French Data", Annales d'économie et de statistique 29: 137-156.

[4] Bourguignon François, Martin Browning and Pierre-André Chiappori, 1995, "The Collective Approach to Household Behavior", Working-Paper, DELTA.

[5] Browning Martin, 1999, "Modelling Commodity Demands and Labour Supply with m-Demands", Working Paper, University of Copenhagen.

[6] Browning Martin, François Bourguignon, Pierre-André Chiappori and Valérie Lechene, 1994, "Incomes and Outcome: A Structural Model of Intrahousehold Allocation", Journal of Political Economy 102: 1067-1096.

[7] Browning Martin and Pierre-André Chiappori, 1998, "Efficient Intra-household Allocations: A General Characterization and Empirical Tests", Econometrica 66 : 12411278.

[8] Browning Martin, Pierre-André Chiappori and Arthur Lewbel, 2004, "Estimating Consumption Economies of Scale, Adult Equivalence Scales, and Household Bargaining Power". Working Paper, University of Copenhagen.

[9] Chiappori Pierre-André, 1988, "Rational Household Labor Supply", Econometrica $56: 63-90$. 
[10] Chiappori Pierre-André, 1992, "Collective Labor Supply and Welfare", Journal of Political Economy 100: 437-467.

[11] Chiappori Pierre-André, Richard Blundell and Costas Meghir, 2006, "Collective Labour Supply with Children", Journal of Political Economy (forthcoming).

[12] Chiappori Pierre-André and Ivar Ekeland, 2003, "The Micro Economics of Group Behavior: Identification", Working Paper, University of Chicago.

[13] Chiappori Pierre-André and Ivar Ekeland, 2006, "Characterizing Group Behavior", Journal of Economic Theory (forthcoming).

[14] Chiappori Pierre-André, Bernard Fortin and Guy Lacroix, 2002, "Marriage Market, Divorce Legislation and Household Labour Supply", Journal of Political Economy $110: 37-72$.

[15] Couprie Hélène, 2003, "Time Allocation within the Family: Welfare Implications of Life in a Couple", Working Paper, GREQAM, Université de la Méditerranée.

[16] Cutler David M. and Lawrence Katz, 1992, "Rising Inequality? Changes in the Distribution of Income and Consumption in the 1980's", American Economic Review $82: 546-551$.

[17] Dauphin, Anyck and Bernard Fortin, 2001, "A Test of Collective Rationality for Multi-person Households", Economics Letters 71: 211-216.

[18] Donni Olivier, 2006, "Collective Consumption and Welfare", Canadian Journal of Economics 39: 124-144.

[19] Donni Olivier, 2007, "Collective Models of the Household", The New Palgrave Dictionary of Economics, Second Edition (forthcoming). 
[20] Donni Olivier and Nicolas Moreau, 2005, "Collective Labor Supply: A SingleEquation Model and Some Evidence from French Data", Working Paper, University of Cergy-Pontoise.

[21] Fong Yuk-fai and Junsen Zhang, 2001, "The Identification of Unobservable Independent and Spousal Leisure", Journal of Political Economy 109 : 191-202.

[22] Hayashi Fulmio, 2000. Econometrics, Princeton, New Jersey: Princeton University Press.

[23] Madden Paul, 1991, "A Generalization of Hicksian q Substitutes and Complements with Application to Demand Rationing", Econometrica 59: 1497-1508.

[24] Mazzocco Maurizio, 2005, "Individual Euler Equations rather than Household Euler Equations", Working Paper, University of Wisconsin-Madison.

[25] Meghir Costas and Gugliemo Weber, 1996, "Intertemporal Nonseparability or Borrowing Restrictions? A Disaggregate Analysis Using a U.S. Consumption Panel”, Econometrica 64: 1151-1181.

[26] Myles Gareth, 1995, Public Economics. Cambridge, U.K.: Cambridge University Press.

[27] Neary J. Peter and Kevin W.S. Roberts, 1980, "The Theory of Household Behavior under Rationing". European Economic Review 13: 25-42.

[28] Nelson Julie, 1988, "Household Economies of Scale in Consumption: Theory and Evidence", Econometrica 56: 1301-1314.

[29] Newey Whitney K. and Kenneth D. West 1987, "Hypothesis Testing with Efficient Method of Moments Estimation". International Economic Review 28: 777-787.

[30] Slesnick Daniel T., 1993, "Gaining Ground: Poverty in the postwar United States", Journal of Political Economy 101: 1-38. 
[31] Thomas Duncan, Dante Contreras and Elizabeth Frankenberg, 1997. "Child Health and the Distribution of Household Resources at Marriage", Working Paper, RAND, University of California at Los Angeles.

[32] Vermeulen Frederic, 2002, "Collective Household Models: Principles and Main Results", Journal of Economic Surveys: 16: 533-564 